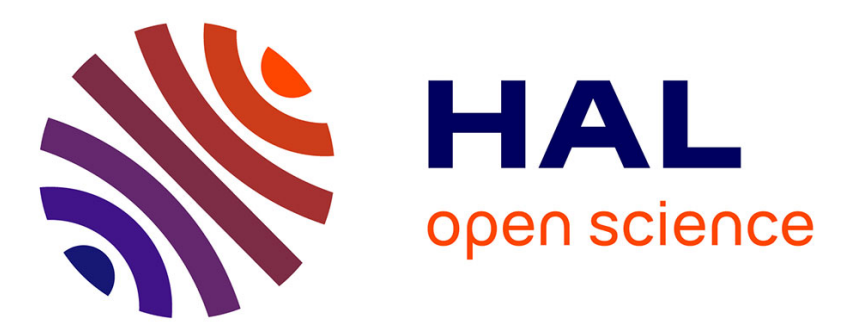

\title{
Preventing Graphene from Restacking via Bioinspired Chemical Inserts: Toward a Superior 2D Micro-supercapacitor Electrode
}

Adnane Bouzina, Hubert Perrot, Ozlem Sel, Catherine Debiemme-Chouvy

\section{To cite this version:}

Adnane Bouzina, Hubert Perrot, Ozlem Sel, Catherine Debiemme-Chouvy. Preventing Graphene from Restacking via Bioinspired Chemical Inserts: Toward a Superior 2D Micro-supercapacitor Electrode. ACS Applied Nano Materials, 2021, 4 (5), pp.4964-4973. 10.1021/acsanm.1c00489 . hal-03243146

\author{
HAL Id: hal-03243146 \\ https://hal.science/hal-03243146
}

Submitted on 2 Jun 2021

HAL is a multi-disciplinary open access archive for the deposit and dissemination of scientific research documents, whether they are published or not. The documents may come from teaching and research institutions in France or abroad, or from public or private research centers.
L'archive ouverte pluridisciplinaire HAL, est destinée au dépôt et à la diffusion de documents scientifiques de niveau recherche, publiés ou non, émanant des établissements d'enseignement et de recherche français ou étrangers, des laboratoires publics ou privés. 


\title{
Preventing Graphene from Restacking via Bioinspired Chemical Inserts: Toward Superior 2D Micro-Supercapacitor Electrode Performance
}

\author{
Adnane Bouzina, Hubert Perrot, Ozlem Sel*, and Catherine Debiemme-Chouvy* \\ Sorbonne Université, CNRS, Laboratoire Interfaces et Systèmes Electrochimiques, LISE, F-75005 Paris, France
}

KEYWORDS. Micro-supercapacitor, EDLC, reduced graphene oxide, polydopamine, composite

\begin{abstract}
Graphene-based composites are promising materials for supercapacitors due to the high specific surface area and electrical conductivity of graphene. Reduction of graphene oxide (GO) is a practical approach to obtain graphene-like material but it suffers from the re-stacking of the graphene sheets. Herein, a two-dimensional composite electrode based on electrochemically reduced GO (ERGO) and polydopamine (PDA) is reported where the PDA is used as a "bioinspired chemical insert" to tackle with the restacking issue of graphene layers. This green and facile electrochemical fabrication method starts from the electro-reduction of GO followed by the electro-oxidation of dopamine (DA), present in the same electrolyte, by a simple switch between a cathodic to an anodic potential. The optimized ERGO-PDA composite electrode possesses combined features of excellent capacitive behavior, with a relaxation time $\left(\tau_{0}\right)$ of $0.88 \mathrm{~s}$, high gravimetric and volumetric capacitances $\left(178 \mathrm{~F} \cdot \mathrm{g}^{-1}\right.$ and $297 \mathrm{~F} \cdot \mathrm{cm}^{-3}$, respectively, at $\left.10 \mathrm{mV} \cdot \mathrm{s}^{-1}\right)$ and finally an excellent cycling stability at 100 to $2000 \mathrm{mV} \cdot \mathrm{s}^{-1}$, at least for 30000 cycles. DA electropolymerization yield monitored by quartz crystal microbalance and X-ray diffraction measurements demonstrate that PDA is formed between the graphene sheets which prevents the sheets from restacking and facilitate species diffusion inside the composite leading to a volumetric energy density of $8.6 \mathrm{mWh} \cdot \mathrm{cm}^{-3}$ for a power density of $7.8 \mathrm{~W} \cdot \mathrm{cm}^{-3}$. Additionally, the electrochemical quartz crystal microbalance demonstrates a dominant cationic charge compensation and a very efficient interfacial transfer characteristics since a totally reversible mass response during charge/discharge was observed for the optimized ERGO-PDA electrode.
\end{abstract}

\section{INTRODUCTION}

The development of miniaturized electrochemical storage systems has garnered increasing attention due to several potential applications as power sources in small-scale electronic devices such as wearable medical systems, wireless sensors, micro-electromechanical devices, and micro-robots. ${ }^{1-3}$

The micro-electrochemical storage devices combine the unique benefits of controllable size and shape, lightweight and flexibility with great electrochemical performances and provide multifunctionality, high efficiency and adaptability for diverse energy storage systems. Currently, the majority of the micro-devices is based on batteries to provide the required energy and power. Despite having a high energy density, the low power density and the limited lifetime of batteries restrict their use for systems that demand high current pulses. ${ }^{4-5}$ Different from the batteries, the electrochemical double layer capacitor (EDLC) possesses a greater power density with rapid charging/discharging capability due to the electrochemical storage of charges through fast and reversible electrostatic attraction at the electrode/electrolyte interface. This type of supercapacitor has many important features such as low cost, long cycle life and high electron transport in the electrode material. ${ }^{6}$ Among various electrode materials, ${ }^{7-9}$ carbon is the main source of EDLC electrode. ${ }^{10-12}$ In this class of materials, graphene with unique characteristics such as large specific surface area $\left(2600 \mathrm{~m}^{2} \cdot \mathrm{g}^{-1}\right)$, high theoretical specific capacitance (550 F.g-1) and high conductivity is deemed as one of the most promising choice. ${ }^{13}$ Various methods have been reported for synthesizing graphene such as mechanical cleavage, ${ }^{14-15}$ epitaxial growth, ${ }^{16-17}$ chemical vapor deposition, ${ }^{18-19}$ electrochemical exfoliation of graphite, ${ }^{20-}$ 24 and reduction of graphene oxide (GO) obtained by the chemical exfoliation of graphite. ${ }^{25}$ Among all these approaches to achieve a graphene-like material, the most favorable route is the reduction of GO and notably the electrochemical reduction of GO that is viewed as an economic, simple, fast and environmentally friendly method with production possibility at a relatively large scale. ${ }^{26-28}$

However, reduced graphene oxide (rGO) suffers from the small surface area due to the partial re-stacking of graphene sheets through $\pi-\pi$ interactions. Therefore, there is a need for developping an effective and feasible route to avoid rGO re-stacking to obtain graphene-based electrodes with a high specific capacitance and a good stability. Several studies have been carried out to prevent the re-stacking of the graphene sheets. ${ }^{29-35}$ These studies mainly focus on two strategies. The first one is to create three-dimensional monoliths with a foamed structure or graphene hydrogels 

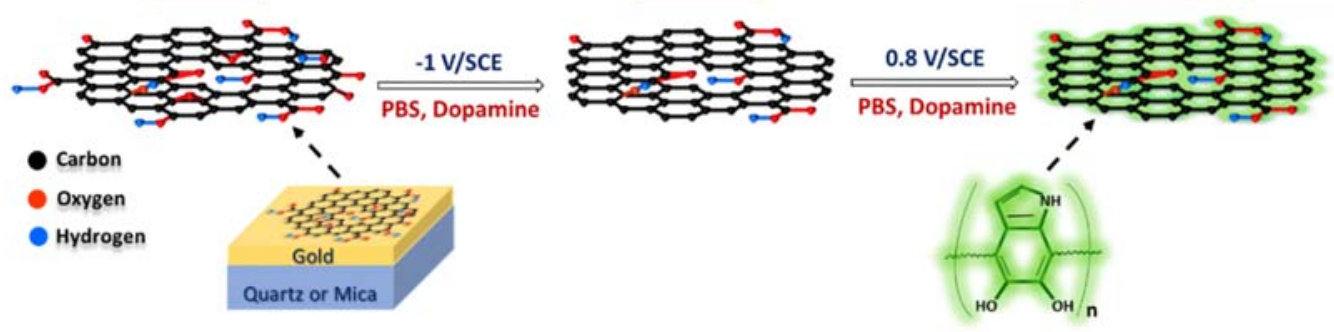

Figure 1. Schematic description of one-pot ERGO-PDA composite film electrosynthesis.

having a plurality of interconnected pores. The second strategy is to pack rGO with a layered structure by combination of additional spacers based on diamines as pillars. ${ }^{29-30}$ Herein, as an alternative to this latter approach, a bio-inspired polymer, polydopamine (PDA), which can be more pertinent for a large scale synthesis, due to its facile and green production was used and evaluated. Polydopamine, a mimic of an adhesive foot protein secreted from mussels, is a product of the (electro)oxidation of dopamine (DA) that contains hydrophilic groups such as catechol and amino groups. ${ }^{36-39}$ The amino group is a good chelating agent for adsorbing a certain amount of metal ions and thus, has the potential of facilitating the ion transfer between the rGO sheets. Moreover, the nitrogen in PDA can enhance the wettability of the material, for example, a thin PDA coating on polyethylene lithium ion battery separator was shown to be beneficial for the electrolyte wetting, the electrolyte uptake, and the ionic conductivity. 40 PDA can not only enhance the wettability of the electrode but can also act as a composite electrode binder, ${ }^{41}$ or as an agent that can increase the adhesion strength between the current collector and the composite electrode. ${ }^{39-41}$ It has recently been employed in the functionalization of water dispersible graphene, providing additional pseudocapacitance to the resulting hybrid electrode without a detrimental effect on the intrinsic electrical transport properties. ${ }^{24}$ Although there are limited number of studies, these previous reports highlight the great potential of PDA as a functional coating on energy storage electrodes and separators.

Motivated by these examples, the present work focuses on graphene-PDA composites as electrodes for microsupercapacitor devices with a facile and relatively environmentally benign electrode preparation. Distinct from the state-of-the-art preparations which are complex and not necessarily compatible with the large scale synthesis, our one-pot method involves the electroreduction of GO which is followed by the electro-oxidation of dopamine, present in the same electrolyte, by a simple switch between a cathodic to an anodic potential. We particularly address the $\mathrm{rGO}$ re-stacking issue by exploiting the PDA as a "chemical insert" between the graphene sheets but also explore the impact of PDA on the interfacial charge storage properties and the cycling performance. For providing a better understanding of the ionic transfer mechanisms occurring at the electrode/electrolyte interface, we employed electrochemical quartz crystal microbalance (EQCM) which complements the electrochemical analysis with in situ gravimetric measurements. ${ }^{42-44}$ Under the gravimetric regime, mass and charge variations measured simultaneously during the electrode cycling allow the global mass per mole of electron (MPE) to be calculated. In the cases where only one species is exchanged, the MPE corresponds to its molar mass which provides the identification of the species exchanged at the electrode/electrolyte interface. ${ }^{26,45}$ Here, EQCM has been used as a gravimetric probe for assessing the impact of PDA on the interfacial ion transfer behavior of electrochemically reduced GO (ERGO) thin film electrodes and corroborated to the charge storage and cycling performance properties.

\section{RESULTS and DISCUSSION}

Thin film electrode preparation. As schematically described in Figure 1, the electroreduction of G0 deposited on the electrode is followed by application of an anodic potential $(0.8 \mathrm{~V}$ vs. SCE), leading to the oxidation of dopamine (DA) molecules and to the formation of PDA. Indeed, once oxidized, DA molecules form radical cations which react to give the insoluble PDA, physically adsorbed at the surface of the working electrode and/or between the ERGO sheets. The PDA continues to grow, as long as the potential is supplied, dissolved dopamine is available and PDA film is not yet insulating. Figure S1a shows the oxidation charge of dopamine on the ERGO coated electrode and the deposited PDA mass estimated by QCM (converting the resonant frequency changes, $\Delta f$ to mass variations, $\Delta m$ using Equation S1) as a function of the electrooxidation time $\left(t_{o x}\right)$. From this figure, it is clear that for $t_{o x}$ less than $300 \mathrm{~s}$, an increase in the electrooxidation time leads to a significant variation of the anodic charge and electrode mass. For tox greater than $300 \mathrm{~s}$, the oxidation charge of DA and the resulting mass show relatively smaller variation with the increase in $t_{o x}$, suggesting the formation of a less conducting PDA polymer after $300 \mathrm{~s}$. Figure S1b shows the variation of the anodic charge and electrode mass under the same conditions but on a bare $\mathrm{Au}$ electrode. These results are compared in Figure $2 \mathrm{a}$ showing the anodic charge dependence of the deposited mass during the electropolymerization of DA on ERGO and on the gold electrode of the quartz resonator. The anodic charge passed 

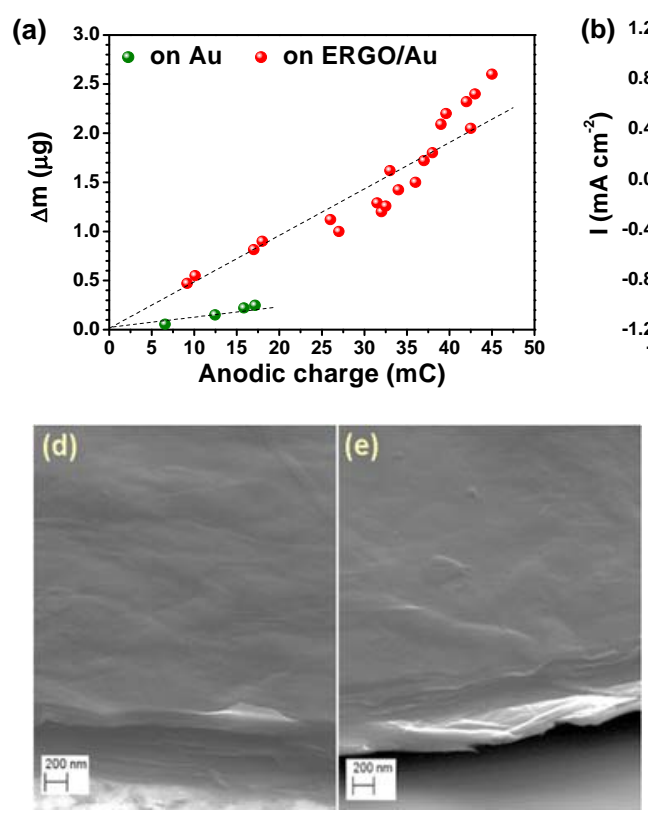
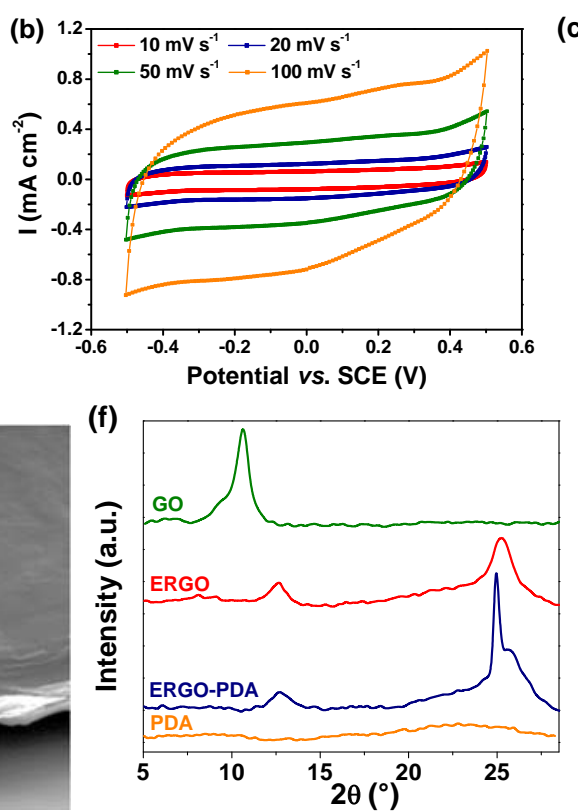
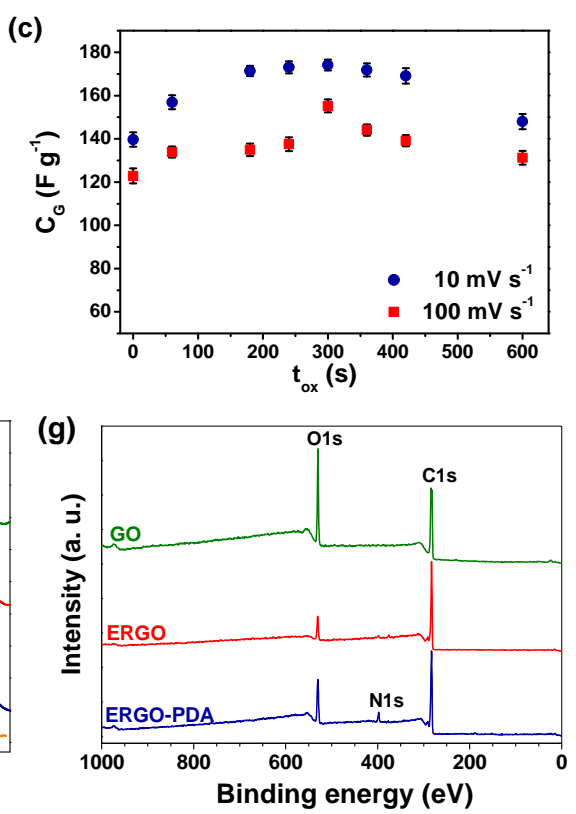

Figure 2. (a) Mass variation vs. anodic charge due to dopamine oxidation on ERGO modified Au electrode of the quartz (red circles) and on blank Au electrode of the quartz (green circles), prepared as comparison. Different $t_{o x}$ were used to synthesize the ERGO-PDA films. Each point correspond to a new electrode preparation, performed under the same conditions. For PDA formed on the bare Au electrode of quartz, the electrodepositon was performed continuously. (b) CV curves of ERGO-PDA prepared with $t_{o x}=420 \mathrm{~s}$. (c) Gravimetric capacitance of ERGO-PDA electrodes with various compositions, at two scan rates (10 and $\left.100 \mathrm{mV}^{\prime} \mathrm{s}^{-1}\right)$, in $0.5 \mathrm{M} \mathrm{Na}^{-} \mathrm{SO}_{4}$ solution; $t_{o x}=0$ corresponds to the ERGO electrode. (d,e) FEG-SEM micrographs of ERGO and ERGO-PDA (with $t_{o x}=300 \mathrm{~s}$ ), respectively. (f) XRD patterns of GO, ERGO, ERGO-PDA and PDA. (g) XPS survey spectra from GO, ERGO and ERGO-PDA films.

through the ERGO modified quartz crystal electrode polarized for $300 \mathrm{~s}$ was about $36 \mathrm{mC}$ (Figure S1a and S2), three times higher than that obtained on blank Au electrode of a quartz resonator with the same geometric surface area. For $t_{o x}=300 \mathrm{~s}$, while $1.5 \mu \mathrm{g}$ of PDA were deposited on the ERGO coated electrode only a ten times lower mass $(0.14 \mu \mathrm{g})$ of PDA was deposited on the black quartz (Figure S1). Moreover the calculation of the yield of the DA electropolymerization reaction shows that $18 \%$ of the oxidized DA was deposited on/in the ERGO deposit whereas only $5 \%$ on the blank quartz. These findings support the idea that PDA is not only formed on the surface of the ERGO electrode but also between the graphene sheets, which will be further corroborated by XRD studies and XPS analyses.

From here on, the electrochemical reduced graphene oxide with PDA will be denoted as ERGO-PDA.

\footnotetext{
Optimization of ERGO-PDA composite, morphological and compositional analyses. To evaluate the effect of PDA on capacitive charge storage properties of ERGO and to find the optimized ERGO-PDA composition, the specific capacitance values were used as an indicator. Figure $2 \mathrm{~b}$ shows the CV curves of ERGO-PDA at a selected $t_{o x}(420 \mathrm{~s})$. The ERGO-PDA electrode presents a quasi-rectangular shape, which indicates a major capacitive behaviour of the composite electrode. To optimize the PDA amount, electrooxidation time of DA has been varied as shown previously (Figure $2 \mathrm{a}$ and $\mathrm{S} 1 \mathrm{a}$ ). From the CV curves of
}

various ERGO-PDA composites obtained by varying $t_{o x}$ (Figure S3) and using Equation 4, gravimetric capacitances $\left(C_{G}\right.$ in $\left.\mathrm{F}^{\cdot} \mathrm{g}^{-1}\right)$ were calculated, the data are shown in Figure 2c. From this figure, it is clearly demonstrated that the introduction of PDA into the ERGO structure significantly improves the gravimetric capacitance of the electrode. Figure 2c shows that after reaching a maximum value for $t_{o x}$ $=300 \mathrm{~s}, \quad C_{G}$ starts to decrease with elongated electrodeposition time due to the formation of a less conducting PDA polymer. It is noted that a significantly high $t_{o x}$ value (1800 s in Figure S3) leads to a marked decrease in the current density of the CV responses, due to the electricalinsulating nature of PDA with high thickness, typically 30-40 $\mathrm{nm}$. From this analysis, the optimized ERGO-PDA composition is determined as $t_{o x}$ of $300 \mathrm{~s}$, and subjected to morphological and electrochemical analysis thereafter. The morphology of the ERGO and ERGO-PDA electrodes was observed by FEG-SEM, the micrographs are shown in Figure $2 \mathrm{~d}$ and $2 \mathrm{e}$, respectively. From these figures, one could notice that the film thickness (about $180 \mathrm{~nm}$ for ERGO and $200 \mathrm{~nm}$ for ERGO-PDA) and surface roughness of ERGO and ERGOPDA electrodes are similar, but the resolution is not enough to localize the PDA content of the composite. XRD analyses were performed at different steps of the composite electrode preparation. Figure $2 \mathrm{f}$ shows the XRD patterns of GO, ERGO and ERGO-PDA electrodes, as well as that of PDA alone which is provided as comparison. The XRD pattern of GO shows (001) diffraction peak at $2 \theta=10.5^{\circ}$ (corresponding to a dspacing of $0.842 \mathrm{~nm}$ ) which is in good agreement with the 
literature values. ${ }^{27,46}$ After electrochemical reduction, the XRD pattern of ERGO presents a shift of the (001) peak to higher $2 \theta$ values and a significant loss in its intensity. Furthermore, a broad (002) peak emerged at $2 \theta=25.3^{\circ}(\mathrm{d}-$ spacing of $0.352 \mathrm{~nm}$ ) which corresponds to a graphite like pattern, 47 indicating the removal of oxygen groups leading to a decrease of the space between the graphene sheets (red pattern in Figure 2f). A significant difference is observed between the XRD pattern of ERGO and that of ERGO-PDA. Indeed, a noteworthy sharp peak which evidences an increase in the crystallinity of the graphene is observed for the ERGO-PDA sample. This sharp peak is located at $25.0^{\circ}$ indicating a higher d-spacing $(0.356 \mathrm{~nm})$ compared to that of ERGO. This finding demonstrates the positive effect of PDA to address the reduced GO re-stacking issue acting as a "chemical insert" between the graphene sheets.

The chemical composition of GO, ERGO and ERGO-PDA films was further investigated by X-ray photoelectron spectroscopy. Figure $2 \mathrm{~g}$ shows the survey spectra obtained for these samples and Table S1 reported the at.\% composition of their surface (10-12 nm). The presence of $\mathrm{N}$ characteristic of the PDA is clearly detected around a binding energy of $400 \mathrm{eV}$ (Figure S4). The atomic ratio $\mathrm{N} / \mathrm{C}$ is
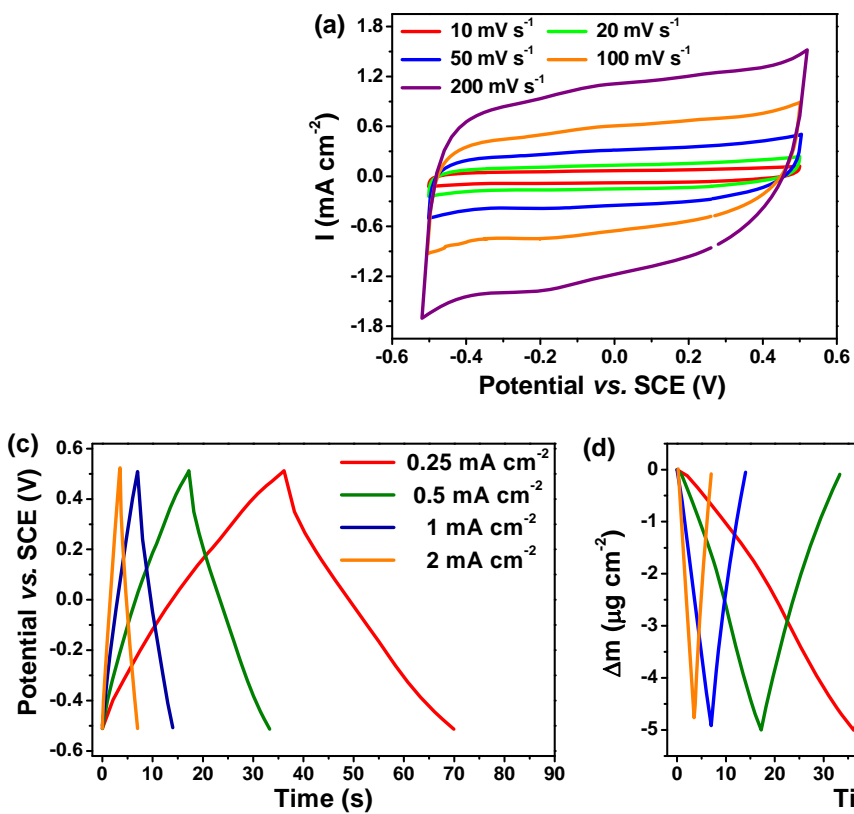

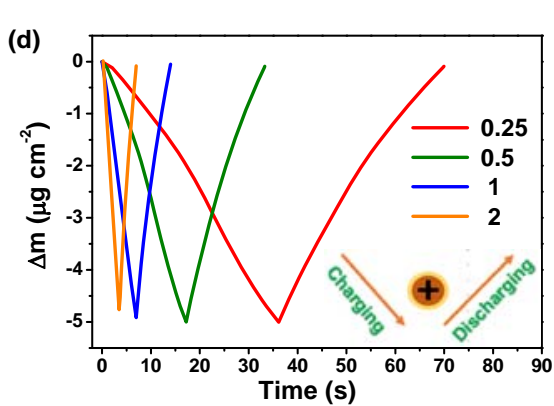

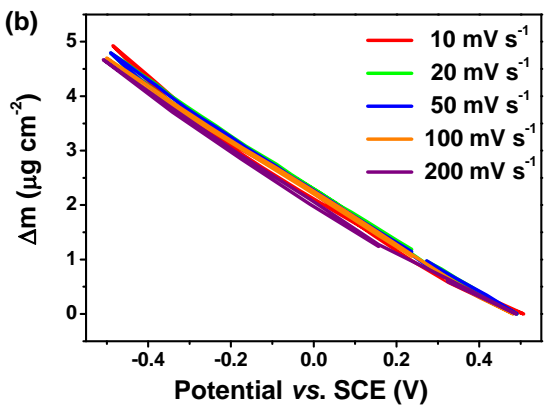

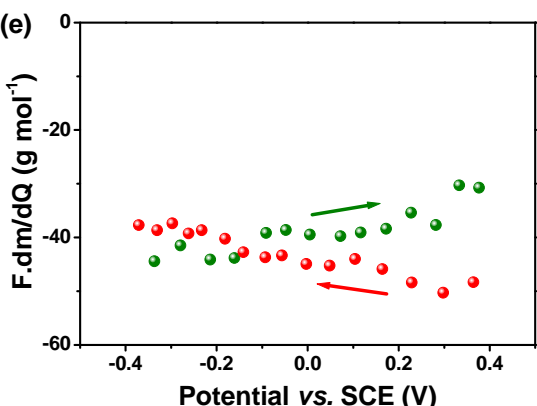

Figure 3. (a) CV and (b) mass change vs. applied potential of the optimized composite ERGO-PDA at different potential scan rates. (c) GCD and (d) mass change vs. time of ERGO-PDA at different charge/discharge current densities in $0.5 \mathrm{M} \mathrm{Na}_{2} \mathrm{SO}_{4}$. Geometric electrode surface area $\left(0.2 \mathrm{~cm}^{2}\right.$ ) is used for the normalization. (e) MPE of ERGO-PDA calculated from EQCM data (QCM coupled to GCD) response at $0.5 \mathrm{~mA} \mathrm{~cm}^{-2}$, at charge (green) and at discharge (red).

0.065 whereas for PDA itself it is higher, it is 0.125 (Table $\mathrm{S} 1) .{ }^{48}$ The low $\mathrm{N} / \mathrm{C}$ ratio indicates that the material is a composite of ERGO and PDA, in good agreement with the C1s spectra (Figure S4).

Investigation of interfacial processes of ERGO-PDA composite by EQCM. To better understand the interfacial processes which are related to the charge storage behaviour of the ERGO-PDA composite, EQCM analyses with two different modes, either coupled to cyclic voltammetry (CV) or galvanostatic charge discharge (GCD), were performed on the optimized composition, i.e. ERGO-PDA obtained after 300 $s$ of DA oxidation (Figure 3 ). It is noted that the ERGO and ERGO-PDA thin film electrodes are suitable for gravimetric QCM studies, supported by the low motional resistance change $(\Delta R)$ with respect to $\Delta f$ values, in air and in the electrolyte (see Supporting Information for more details). The CV curves in Figure 3 a present a quasi-rectangular shape, in agreement with those of ERGO-PDA previously shown in Figure $2 \mathrm{~b}\left(t_{o x}=420 \mathrm{~s}\right)$ and Figure S3. The chargedischarge curves of ERGO-PDA in $0.5 \mathrm{M} \mathrm{Na}_{2} \mathrm{SO}_{4}$ (Figure $3 \mathrm{c}$ ) are almost linear, indicating a typical double-layer capacitance behaviour, i.e. reversible electroadsorption/desorption of ionic species present in the electrolyte. To investigate this interfacial electoadsorption/desorption process, the corresponding mass profiles were examined. Figure $3 \mathrm{~b}$ and $3 \mathrm{~d}$ indicate that the cations dominate this process, as during a cathodic and an anodic sweep of the potential, the electrode mass increases and decreases, respectively. One can also notice that the magnitude of the normalized mass change occurring during either CV (Figure 3b) or a GCD cycle (Figure 3d) for ERGO-PDA is larger than those for pristine ERGO (Figure S5c and S5d), suggesting a larger specific surface area for the electroadsorption/desorption process. The behavior of the ERGO-PDA and ERGO electrodes during cycling present another remarkable difference (Figure $3 b$ and $55 c$ ). In the case of ERGO-PDA (Figure 3b), a totally reversible mass response is observed (cathodic and anodic scans) whereas a hysteresis is noticed for that of pristine ERGO (Figure S5c). The absence of a hysteresis for ERGO-PDA electrode 
indicates that the interfacial processes, electroadsorption/desorption of the active species, occur at a very similar rate (Figure $3 \mathrm{~b}$ ).

Moreover Figure $3 \mathrm{e}$ depicts the MPE calculated using Equation 8 from the GCD coupled QCM response. Here, a MPE of $41 \mathrm{~g} \cdot \mathrm{mol}^{-1}$ is obtained. This value corresponds to the molar mass of $\mathrm{Na}^{+}$ions $\left(23 \mathrm{~g} \mathrm{~mol}^{-1}\right)$ with a hydration number of 1. However, GCD and CV coupled to QCM alone are not qualified to unambiguously identify the contribution of each species (cation, anion or solvent molecule) present in the electrolyte. In order to deconvolute the global electrogravimetric response into distinct contributions (in case of multi species presence) from each species and obtain kinetic information about their interfacial transfer, another coupled electrochemical method "QCM with electrochemical impedance spectroscopy (EIS) (so-called, acelectrogavimetry)" is planned as a complementary tool to the EQCM. ${ }^{26-27,49}$

Charge storage performance evaluation of ERGOPDA composite. The gravimetric and volumetric capacitance values are calculated using Equation 4 and 5. The optimized composite offers an increased gravimetric capacitance compared to that of pristine ERGO (Figure S6) (equals to $178 \mathrm{~F} \cdot \mathrm{g}^{-1} \mathrm{vs} .142 \mathrm{~F} \cdot \mathrm{g}^{-1}$ at $10 \mathrm{mV} \cdot \mathrm{s}^{-1}$ ), which is higher than that of most graphene based electrode.27, 50 As shown in Figure 4a, the obtained volumetric capacitance of the ERGO-PDA electrode is as high as $297 \mathrm{~F} \cdot \mathrm{cm}^{-3}$ (vs. 210 $\mathrm{F} \cdot \mathrm{cm}^{-3}$ for ERGO) at a scan rate of $10 \mathrm{mV} \cdot \mathrm{s}^{-1}$, which is comparable to the highest value among those reported for carbon-based
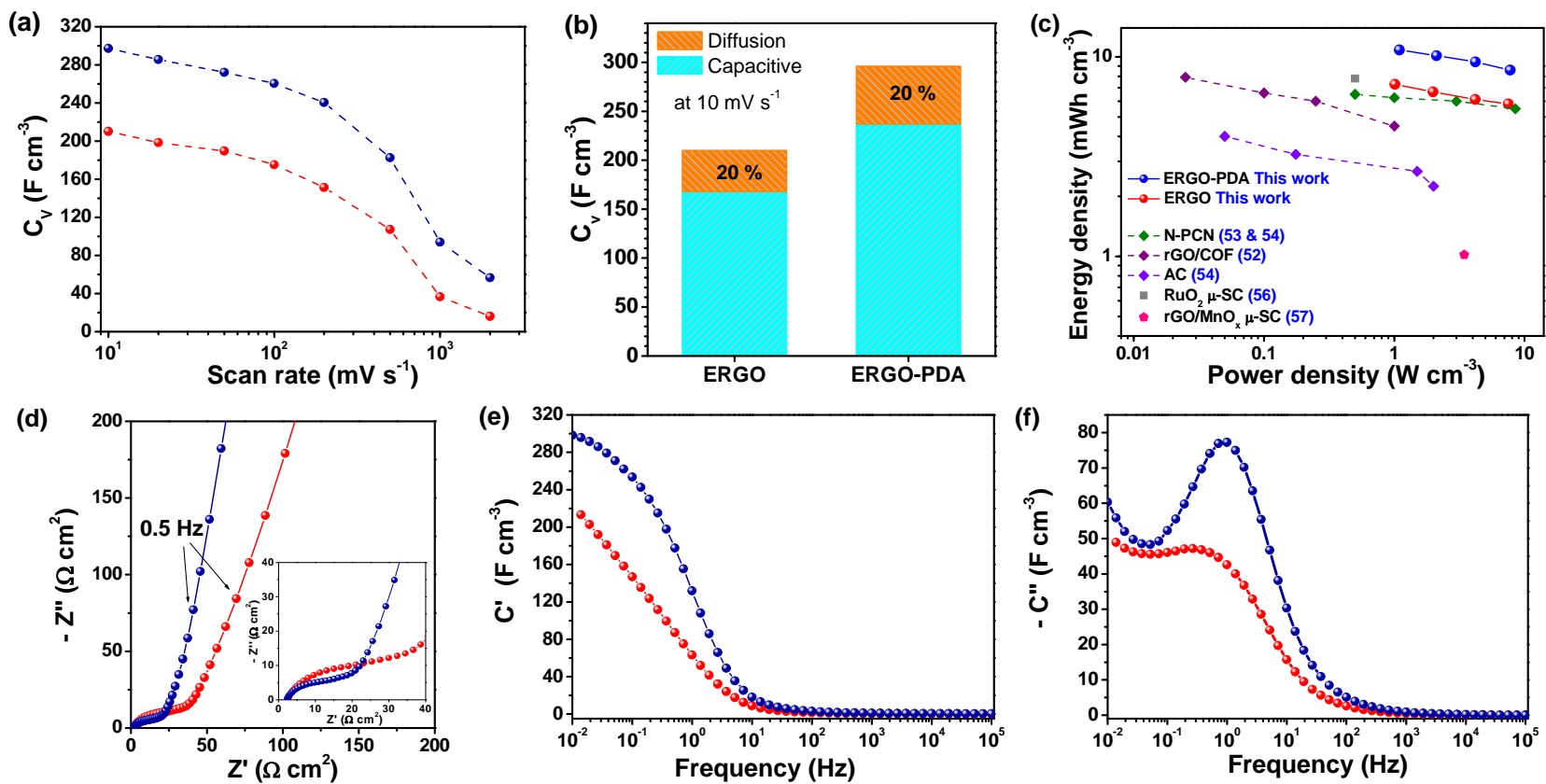

Figure 4. (a) Volumetric capacitance of ERGO (red scatters) and ERGO-PDA (blue scatters) films determined from CVs performed at different potential scan rates, in $0.5 \mathrm{M} \mathrm{Na}_{2} \mathrm{SO}_{4}$. (b) Capacitive and diffusion contributions of capacitance of ERGO and ERGO-PDA electrodes. (c) Ragone plot of the ERGO and ERGO-PDA in comparison with some recent studies. (d) Nyquist plot. Inset: zoom from 0 to $40 \Omega \mathrm{cm}^{2}$. (e) and (f) Bode plots of the volumetric capacitance of ERGO (red scatters) and ERGO-PDA (blue scatters) in the frequency range of $0.01 \mathrm{~Hz}$ to $10 \mathrm{kHz}$, measured at $-0.3 \mathrm{~V}$ vs. SCE in $0.5 \mathrm{M} \mathrm{Na}_{2} \mathrm{SO}_{4}$

electrodes for EDLCs. ${ }^{24-30}$ These findings suggest an enhancement of ion access to the active sites between the graphene sheets and an increase of the specific surface area. Additionally, ERGO-PDA shows a good rate capability, such that $81 \%$ of the initial value is maintained when the scan rate is increased from $10 \mathrm{mV} \cdot \mathrm{s}^{-1}$ to $200 \mathrm{mV} \cdot \mathrm{s}^{-1} \mathrm{vs}$. $72 \%$ for pristine ERGO (Figure 4a). Although the absolute values for $C_{G}$ and $C_{V}$ show an eventual decrease at very high scan rates (Figure 4a and S6), the improvement in the presence of PDA is persistent at the all potential scan rates tested (10-2000 $\mathrm{mV} \cdot \mathrm{s}^{-1}$ ) and the cycling performance of the ERGO-PDA electrodes at very high scan rates will be evaluated in the last section. The high rate capability allows more amount of energy to be stored at high current density which is particularly suitable for a combination of rapid charge/discharge and high energy delivery ability. To evaluate and compare the capacitive energy storage behavior of ERGO and ERGO-PDA films, Trasatti's method was used (Figure S7). ${ }^{51-52}$ It allows to determine the contributions of the surface controlled (EDLC) and the diffusion-controlled (pseudo-capacitance) processes. This analysis shows that for ERGO as well as for ERGO-PDA 80\% of the capacitance is due to EDLC and $20 \%$ to diffusion.(Figure 4b)

Furthermore, the energy and power densities of the electrodes were calculated based on the GCD profiles (Figure $3 c)$, the corresponding volumetric specific capacitance values are presented in Figure S8. In Figure 4c the Ragone plot of the ERGO-PDA composite is compared to that of the pristine ERGO electrode, as well as to the state of the art carbon based electrodes reported in literature. The ERGOPDA can achieve a volumetric energy density of 10.84 mWh.cm ${ }^{-3}$ at a power density of $1.09 \mathrm{~W} \cdot \mathrm{cm}^{-3}$ vs. only 7.3 $\mathrm{mWh} \cdot \mathrm{cm}^{-3}$ at a lower power density for ERGO, further 
demonstrating the enhanced charge storage behavior in the presence of PDA. Even at a power density of $7.75 \mathrm{~W} \cdot \mathrm{cm}^{-3}$, the optimized ERGO-PDA composite can still deliver an energy density of $8.58 \mathrm{mWh} \cdot \mathrm{cm}^{-3}$, which is superior or comparable to the reports on carbon-based electrodes tested in aqueous electrolytes. ${ }^{52-54}$ In addition, compared to flexible and micro-capacitors; ${ }^{55-57}$ ERGO-PDA exhibits a higher energy density at a comparable power density (Figure 4c).

Impedance analyses of ERGO-PDA composite. In order to complete the electrochemical characterization of this new composite and to better evaluate its electrochemical performance, electrochemical impedance spectroscopy (EIS) analyses were performed. Figure $4 \mathrm{~d}$ compares EIS data obtained at $-0.3 \mathrm{~V} v s$. SCE of ERGO and ERGO-PDA in the Nyquist representation. The first intersection with the x-axis at the highest frequency $\left(R_{s}\right)$ is about $2 \Omega \cdot \mathrm{cm}^{2}$ for the both electrodes (Inset Figure $4 \mathrm{~d}$ ), this resistance is mainly attributed to the electrical resistance of the electrode, together with the resistance of the bulk electrolyte. ${ }^{58}$ At intermediate frequencies, the diameter of the semicircle is attributed to the interfacial charge-transfer resistance $\left(R_{C T}\right)$, which is estimated as $34 \Omega \cdot \mathrm{cm}^{2}$ for pristine ERGO, while that of ERGO-PDA is only $22 \Omega \cdot \mathrm{cm}^{2}$. This demonstrates the enhanced charge transfer of the ERGOPDA which can be related to a better regulation of the electrolyte wetting by the introduction of PDA into the ERGO structure.

The highest capacitance values are usually obtained from GCD cycles recorded at a specific current density or from CV measurements obtained at a specific scan rate. However, for EDLC electrodes, the capacitance is frequency dependent, and can be determined using EIS. The frequency dependence of complex capacitance is often used to study the energy storage mechanism and is calculated as follows ${ }^{59}$ :

$$
\begin{aligned}
& C^{\prime}(\omega)=\frac{-Z^{\prime \prime}(\omega)}{\omega|Z(\omega)|^{2}} \\
& C^{\prime \prime}(\omega)=\frac{-Z^{\prime}(\omega)}{\omega|Z(\omega)|^{2}} \\
& C(\omega)=C^{\prime}(\omega)-j C^{\prime \prime}(\omega)
\end{aligned}
$$

where $Z^{\prime}, Z^{\prime \prime}$ and $Z$ are the real, imaginary and total impedance values, respectively in ohms, with $j^{2}=-1$. The entities $C^{\prime}, C^{\prime \prime}$ and $C$ represent the real part, imaginary part and total capacitance, respectively, at a given frequency. The real value of the capacitance of the electrode could be determined by $C^{\prime}(\omega)$ values at low frequency under these conditions the ions have enough time to
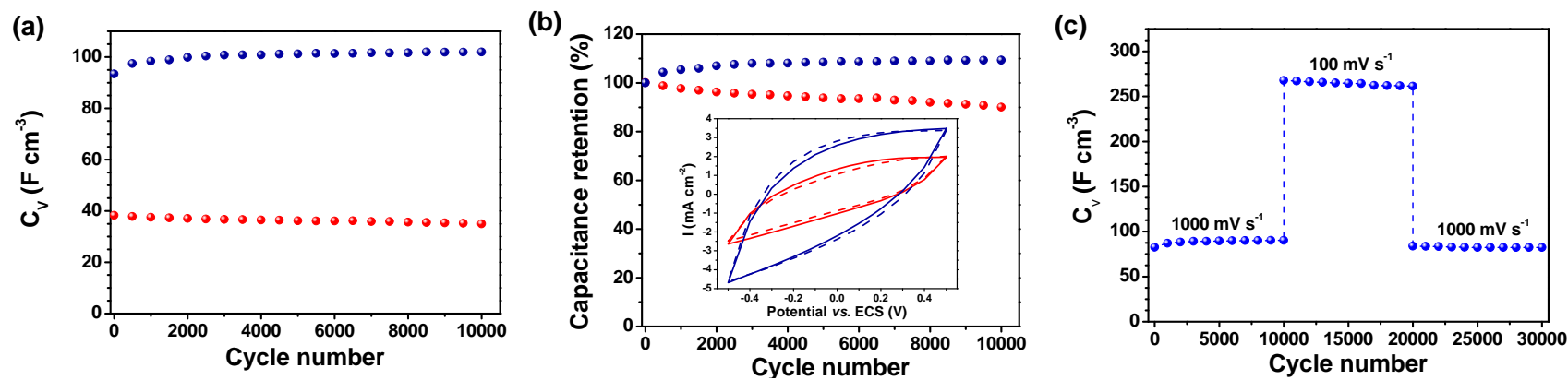

Figure 5. Evolution of (a) volumetric capacitance and (b) capacitance retention of ERGO (red) and ERGO-PDA (blue) as a function of the number of cycles at $1000 \mathrm{mV} \cdot \mathrm{s}^{-1}$. (c) Evolution of volumetric capacitance of ERGO-PDA as a function of the number of cycles at various scan rates, measured consecutively. Electrolyte: $0.5 \mathrm{M} \mathrm{Na}_{2} \mathrm{SO}_{4}$. Inserts: $1^{\text {st }}$ (full line) and $10000^{\text {th }}$ (dash line) cycles.

reach the real electrode surface. In Figure S9, the curves exhibit a relatively suppressed loop which can be related to a composition z of several loops. It indicates the contribution of more than one charged species with similar time constant. At this level, it is not possible to identify the different charged species, only a complementary method of investigation can permit this discrimination. Nevertheless, these results are totally coherent with previous results obtained for ERGO films tested under similar conditions. ${ }^{27}$ It is noted that the diameter of the loop is bigger in the case of the ERGO-PDA composite film compared to that obtained with the pristine ERGO film: it indicates a better capacity of the former to uptake the different ions during an electrochemical charge process. The change in specific capacitance as a function of frequency for ERGO and ERGO-PDA is shown in Figure $4 \mathrm{e}$ and $4 \mathrm{f}$. The maximum capacitance at low frequency is close to $300 \mathrm{~F} \cdot \mathrm{cm}^{-3}$ for ERGO-PDA vs. $213 \mathrm{~F} \cdot \mathrm{cm}^{-3}$ for pristine ERGO (Figure $4 \mathrm{e}$ ). These results are consistent with the volumetric capacitance values extracted from the CV data (Figure 4a). As the frequency increases the ions can no longer follow the applied potential, they do not reach the bottom of the electrode pores which leads to a significant decrease of $C^{\prime}$ (Figure $4 \mathrm{e}$ ). The evolution of the imaginary capacitance, $C^{\prime \prime}(\omega)$, is also presented in Figure $\left.4 \mathrm{f}\right)$. $C^{\prime \prime}(\omega)$ attains a maximum at a characteristic frequency $\left(f_{0}\right)$ of $0.24 \mathrm{~Hz}$ and $1.14 \mathrm{~Hz}$ for ERGO and ERGO-PDA, respectively, due to the combined effect of resistive components dissipating energy through ohmic losses and capacitive components that store electrical energy, simultaneously. ${ }^{59-61}$ When approaching $f_{0}$, the dispersed energy increases drastically because only a few charges are stored on the electrode surface, the system becomes more resistive. After attaining a maximum value, at the lower frequency region, these losses decrease rapidly and the system becomes more capacitive. The relaxation time $\left(\tau_{0}\right)$ that represents the minimum time for discharging all the energy from the electrode with an efficiency of $50 \%$ can be expressed as the inverse of the characteristic frequency $\left(\tau_{0}=1 / f_{0}\right)$. In our case, the relaxation time of the ERGO and ERGO-PDA is found to be $4.1 \mathrm{~s}$ and $0.88 \mathrm{~s}$, respectively. That is to say, the ERGO-PDA electrode exhibits excellent rate capability. 
Cycling performance of ERGO-PDA composite. The cycling performances of the electrodes were evaluated by the repeated CV cycles at a high scan rate of $1000 \mathrm{mV} \cdot \mathrm{s}^{-1}$ in the potential range of -0.5 to $0.5 \mathrm{~V} v s$. SCE for 10000 cycles, in $0.5 \mathrm{M} \mathrm{Na}_{2} \mathrm{SO}_{4}$ solution. As illustrated in Figure $5 \mathrm{a}$ and $5 \mathrm{~b}$, about $107 \%$ of capacitance retention is achieved for ERGOPDA electrode while only $87 \%$ of the initial $C_{v}$ value is retained for the pristine ERGO electrode, further demonstrating the advantage of PDA incorporation in ERGO. The remarkable cycling stability of the ERGO-PDA composite at different potential scan rates is illustrated in Figure $5 \mathrm{c}$ and Figure S10. The $C_{V}$ values obtained at $1000 \mathrm{mV}^{\cdot} \mathrm{s}^{-1}$ remained unchanged, when an additional cycling step $(10000$ cycles at $100 \mathrm{mV}^{*} \mathrm{~s}^{-1}$ ) was added, which results in a stability for at least 30000 cycles. Further increase of the scan rate at $2000 \mathrm{mV}$ 's ${ }^{1}$ also reflects the good performance of the ERGO-PDA, the $C_{V}$ values were kept intact during the measured 10000 cycles (Figure S10). At the beginning of the cycling the capacitance slightly increases, this finding could be explained by the activation of the material due to the continuous diffusion of the ions inside the deep pores of the composite, which leads to a full wetting of the ${ }^{62-63}$ Additionally, as shown in Figure S11, the EIS recorded after 10000 cycles at scan rate of 1000 $\mathrm{mV} \cdot \mathrm{s}^{-1}$ shows a further decrease in charge transfer resistance of ERGO-PDA, suggesting that the electrode has become more accessible to the electrolyte as the number of cycles increased, whereas for ERGO, $R_{C T}$ slightly increases after cycling, which is in line with the lower capacitance retention of the pristine ERGO compared with the ERGO-PDA composite.

\section{CONCLUSIONS}

In summary, electrochemically reduced graphene oxide and polydopamine composites were successfully synthesized via a facile electrochemical approach where the PDA has played the essential role in tackling with the re-stacking issue of the graphene layers. The optimized ERGO-PDA composite presents high volumetric and gravimetric capacitance values, a remarkable cycling stability (for about at 30000 cycles without a noticeable decrease of $C_{V}$ values at 1000 $\mathrm{mV} \mathrm{s}^{-1}$ ) and an efficient interfacial ion transfer characteristic with a better capacitive behavior compared to pristine ERGO. The enhanced electrochemical performance is attributed to the incorporation of PDA that polymerizes between the reduced graphene oxide sheets. The formation of PDA occurs not only on the surface of ERGO electrode but also between the graphene sheets which was demonstrated by the changes in the d-spacing values and graphene crystallinity estimated by XRD. Supporting these results, QCM monitoring of the PDA electropolymerization process revealed a factor of more than three in the yield of the DA electropolymerization reaction (18\% of the oxidized DA was deposited in the ERGO film vs. only $5 \%$ on blank quartz for a $t_{o x}$ of $300 \mathrm{~s}$ ). Therefore, the superior performance metrics are attributed to the PDA incorporation which prevents the ERGO from re-stacking and enhances the electrolyte wettability of the electrode, thanks to its nitrogen functionalities. Here, the favorable impact of PDA is shown on reduced graphene oxide, shedding light on the design of graphene based composite electrodes and can be extended to other 2D materials for high-performance electrochemical energy storage electrodes.

\section{MATERIALS and METHODS}

GO suspension ( $4 \mathrm{mg} / \mathrm{mL}$, dispersion in $\mathrm{H}_{2} \mathrm{O}$ ) was purchased from Sigma Aldrich and diluted to $1 \mathrm{mg} / \mathrm{mL}$ of GO. Dopamine (DA) hydrochloride, potassium phosphate monobasic $\left(\mathrm{KH}_{2} \mathrm{PO}_{4}\right)$, potassium phosphate dibasic $\left(\mathrm{K}_{2} \mathrm{HPO}_{4}\right)$, and sodium sulfate $\left(\mathrm{Na}_{2} \mathrm{SO}_{4}\right)$ were procured from Sigma Aldrich and used without further purification. Double distilled water (18.2 $\mathrm{M} \Omega^{\circ} \mathrm{cm}$, Purelab flex ELGA, water purification system)

was employed for all solution preparations. Phosphate buffered saline solution (PBS) of $\mathrm{pH} 7.2$ was obtained by mixing $0.1 \mathrm{M}$ of $\mathrm{KH}_{2} \mathrm{PO}_{4}$ and $0.1 \mathrm{M}$ of $\mathrm{K}_{2} \mathrm{HPO}_{4}$.

\section{Synthesis of ERGO-PDA electrode}

Figure 1 shows the schematic description of the ERGO-PDA synthesis. For the EQCM studies, about $6 \mu \mathrm{L}$ of the GO suspension were deposited on the gold electrode $\left(0.2 \mathrm{~cm}^{2}\right)$ of a quartz resonator ( $9 \mathrm{MHz}$, AWSensors, Spain). GO film was generated after being dried at $70{ }^{\circ} \mathrm{C}$ in an oven, at atmospheric pressure. The electrochemical preparation of the composite was carried out using a standard three electrode configuration with an Autolab potentiostat (Metrohm, France) where GO-coated gold electrode of quartz was used as the working electrode, with a platinum grid and saturated calomel electrode (SCE) as a counter electrode and a reference electrode, respectively.

The ERGO film was electrochemically synthesized under a chronoamperometry mode at $-1 \mathrm{~V} v$ s. SCE for 10 minutes in a solution of $0.2 \mathrm{M}$ PBS (pH 7.2) containing $5 \times 10^{-3} \mathrm{M}$ of dopamine $(1 \mathrm{mg} / \mathrm{mL})$, the $I(t)$ curve is depicted in Figure $S 2 \mathrm{a}$. In a consecutive step, the polydopamine (PDA) was electrosynthesized by chronoamperometry at $0.8 \mathrm{~V} v S$. SCE for different times $\left(t_{o x}\right)$, one $I(t)$ curve is shown in Figure S2b. Gold coated mica was also used as substrates for the morphological characterizations of the ERGO and ERGO-PDA layers, for the sake of practicality. Otherwise, the same electrode synthesis procedure was followed. The mass loading, thickness and density of the electrodes are estimated to be $5.3 \mu \mathrm{g} ; 180 \mathrm{~nm} ; 1.47 \mathrm{~g} \cdot \mathrm{cm}^{-3}$, respectively, for ERGO and $6.7 \mu \mathrm{g} ; 200 \mathrm{~nm} ; 1.67 \mathrm{~g} \cdot \mathrm{cm}^{-3}$, respectively, for ERGO-PDA electrodes ( $\mathrm{S}=0.2 \mathrm{~cm}^{2}$ ).

\section{Characterization of the electrodes}

Morphological and compositional characterization of the electrodes:

The morphological aspect of the ERGO and ERGO-PDA films was examined under a field emission gun scanning electron microscope (FEG-SEM) (Ultra55, Zeiss) operating at $5 \mathrm{kV}$. Xray photoelectron spectroscopy (XPS) analyses were performed using an Omicron Argus X-ray photoelectron spectrometer with monochromatized $\mathrm{Al} \mathrm{K \alpha}$ excitation $(1486.6 \mathrm{eV})$ with a pass energy of $100 \mathrm{eV}$ and $20 \mathrm{eV}$ for acquisition of the survey and high-resolution spectra, respectively. The XPS peak areas were determined after subtraction of a background using the Shirley's method. Element peak intensities were corrected by Scofield factors. All spectrum processing was carried out using Casa XPS software (Casa Software Ltd., UK). For the XPS analyses, the films were prepared on gold-coated mica substrate. X-ray diffraction (XRD) was performed using Philips PANalytical 
X'Pert Pro diffractometer with $\mathrm{Cu}$ K $\alpha$ radiation $(\lambda=1.54184$ $\AA$ ). The samples were prepared on ITO coated glass substrate.

Electrochemical and electrogravimetric characterizations:

The electrochemical performances were measured employing a standard three-electrode electrochemical cell, which was consisted of an ERGO or ERGO-PDA loaded quartz resonator as the working electrode, SCE as the reference and platinum grid as the counter electrode.

Cyclic voltammetry (CV) and galvanostatic charge discharge (GCD) were carried out at ambient temperature in $0.5 \mathrm{M}$ $\mathrm{Na}_{2} \mathrm{SO}_{4}$ solution, with a potential window from -0.5 to $0.5 \mathrm{~V}$ $v s$. SCE. The electrochemical impedance spectroscopy (EIS) as conducted in a frequency range from $100 \mathrm{kHz}$ to $0.01 \mathrm{~Hz}$ at $-0.3 \mathrm{~V} v s$. SCE, with a potential perturbation amplitude of $10 \mathrm{mV}$.

The gravimetric capacitance $\left(C_{G}\right)$ and the volumetric capacitance $\left(C_{V}\right)$ of the working electrode were calculated from the cyclic voltammetry (CV) curve by using the formula:

$C_{G}=\frac{1}{2 m v\left(E_{2}-E_{1}\right)} \int_{E_{1}}^{E_{2}} I(E) d E$

$C_{V}=\frac{1}{2 V_{f} v\left(E_{2}-E_{1}\right)} \int_{E_{1}}^{E_{2}} I(E) d E$

where $v$ is the potential scan rate, $E_{1}$ and $E_{2}$ are the low and high end potentials, $I(E)$ is the response in current. For $C_{G}, m$ is the mass loading of the electrode by ERGO or ERGO-PDA estimated by QCM measurements (see below). For $C_{V}, V_{f}=S$ $e$, it is the estimated film volume where $S$ is the geometrical surface $\left(0.2 \mathrm{~cm}^{2}\right)$ and $e$ is the thickness of ERGO or ERGOPDA films determined by FEG-SEM observation of the sample cross-section.

The energy density $(E)$ and the power density $(P)$ of the working electrode are calculated from the galvanostatic charge discharge (GCD) curve according to Equation 6 and 7:

$E=\frac{C_{V} \Delta V^{2}}{2 \times 4 \times 3600}$

$P=\frac{3600 E}{\Delta t}$

where $C_{V}$ is the volumetric capacitance (Equation 5), $\Delta V$ represents the voltage window and $\Delta t$ is the discharge time.

For the EQCM analyses, either CV or GCD were coupled with the QCM measurements to obtain the simultaneous frequency changes, $\Delta f$, of the modified quartz resonators during the electrochemical processes. The corresponding mass profile, $\Delta m$, was obtained from $\Delta f$, using the Sauerbrey equation (Equation S1) ${ }^{64}$ with the experimental sensitivity

1. Luo, S.; Hoang, P. T.; Liu, T., Direct laser writing for creating porous graphitic structures and their use for flexible and highly sensitive sensor and sensor arrays. Carbon 2016, 96, 522531.

2. $\quad$ Smith, J.; Bawolek, E.; Lee, Y. K.; O'Brien, B.; Marrs, M.; Howard, E.; Strnad, M.; Blain Christen, J.; Goryll, M., Application of flexible flat panel display technology to wearable biomedical devices. Electronics Letters 2015, 51, 1312-1314.

3. Fukagawa, H.; Sasaki, T.; Tsuzuki, T.; Nakajima, Y.; Takei, T.; Motomura, G.; Hasegawa, M.; Morii, K.; Shimizu, T., Long-Lived Flexible Displays Employing Efficient and Stable constant equals to $16.31 \times 10^{7} \mathrm{~Hz} \mathrm{~g}^{-1} \mathrm{~cm}^{2}$ for a quartz resonator operating at $9 \mathrm{MHz}$. 65

The applicability of the gravimetric conditions were verified by analyzing the motional resistance change, $\Delta R$, (with)out loading in air and in the electrolyte, using electroacoustic admittance measurements (Figure S12 and S13). ${ }^{66}$ The loadings of the electrodes were also calculated by measuring $\Delta f$ (the difference between blank quartz and loaded quartz frequency in air) and converting it to $\Delta m$ using Equation S1. The $M P E$ values were calculated from the EQCM data using: $M P E=F \frac{\Delta m}{\Delta q}$

where $\mathrm{F}$ is the Faraday number, $\Delta m$ and $\Delta q$ are the mass and charge variations, respectively.

\section{ASSOCIATED CONTENT}

Supporting Information. Table with at.\% determined by XPS, for GO, ERGO and ERGO-PDA. Further results of ERGO, ERGOPDA synthesis $(I(t))$ and electrochemical characterization $(I(V)$, $M P E(V)$, GCD curves, Nyquist plot after cycling). Theoretical background and experimental results of electroacoustic admittance measurements.

This material is available free of charge via the Internet at http://pubs.acs.org.

\section{AUTHOR INFORMATION}

\section{Corresponding Authors}

*E-mail: ozlem.sel@sorbonne-universite.fr

*E-mail: catherine.debiemme-chouvy@sorbonne-universite.fr

\section{ORCID}

Hubert Perrot: 0000-0002-3930-2968

Ozlem Sel: 0000-0002-8501-4561

Catherine Debiemme-Chouvy: 0000-0001-7171-6039

\section{Funding Sources}

Ecole doctorale, ED388, French Ministry of Education Scholarship.

\section{Notes}

The authors declare no competing financial interest.

\section{ACKNOWLEDGMENT}

We thank Ms. Françoise Pillier for the FEG-SEM observations and Dr. Cyrille Bazin for the XRD analyses.

\section{REFERENCES}

Inverted Organic Light-Emitting Diodes. Advanced Materials 2018, 30, 1706768.

4. $\quad$ Brousse, K.; Pinaud, S.; Nguyen, S.; Fazzini, P.-F.; Makarem, R.; Josse, C.; Thimont, Y.; Chaudret, B.; Taberna, P.-L.; Respaud, M.; Simon, P., Facile and Scalable Preparation of Ruthenium Oxide-Based Flexible Micro-Supercapacitors. Advanced Energy Materials 2020, 10, 1903136.

5. Beidaghi, M.; Gogotsi, Y., Capacitive energy storage in micro-scale devices: recent advances in design and fabrication of micro-supercapacitors. Energy \& Environmental Science 2014, 7, 867-884. 
6. Simon, P.; Gogotsi, Y., Materials for electrochemical capacitors. Nature Materials 2008, 7, 845-854.

7. Liu, Y.; Zhang, B.; Xu, Q.; Hou, Y.; Seyedin, S.; Qin, S.; Wallace, G. G.; Beirne, S.; Razal, J. M.; Chen, J., Development of Graphene Oxide/Polyaniline Inks for High Performance Flexible Microsupercapacitors via Extrusion Printing. Advanced Functional Materials 2018, 28, 1706592.

8. Wang, Y.; Chen, Z.; Lei, T.; Ai, Y.; Peng, Z.; Yan, X.; Li, H.; Zhang, J.; Wang, Z. M.; Chueh, Y.-L., Hollow NiCo2S4 Nanospheres Hybridized with 3D Hierarchical Porous rGO/Fe203 Composites toward High-Performance Energy Storage Device. Advanced Energy Materials 2018, 8, 1703453.

9. $\quad$ Zhu, S.; Li, L.; Liu, J.; Wang, H.; Wang, T.; Zhang, Y.; Zhang, L.; Ruoff, R. S.; Dong, F., Structural Directed Growth of Ultrathin Parallel Birnessite on $\beta$-MnO2 for High-Performance Asymmetric Supercapacitors. ACS Nano 2018, 12, 1033-1042.

10. Li, Z.; Zhang, L.; Amirkhiz, B. S.; Tan, X.; Xu, Z.; Wang, H.; Olsen, B. C.; Holt, C. M. B.; Mitlin, D., Carbonized Chicken Eggshell Membranes with 3D Architectures as High-Performance Electrode Materials for Supercapacitors. Advanced Energy Materials 2012, 2, 431-437.

11. Béguin, F.; Presser, V.; Balducci, A.; Frackowiak, E., Carbons and Electrolytes for Advanced Supercapacitors. Advanced Materials 2014, 26, 2219-2251.

12. Titirici, M.-M.; White, R. J.; Brun, N.; Budarin, V. L.; Su, D. S.; del Monte, F.; Clark, J. H.; MacLachlan, M. J., Sustainable carbon materials. Chemical Society Reviews 2015, 44, 250-290.

13. Tan, Y. B.; Lee, J.-M., Graphene for supercapacitor applications. Journal of Materials Chemistry A 2013, 1, 1481414843.

14. Novoselov, K. S.; Geim, A. K.; Morozov, S. V.; Jiang, D.; Zhang, Y.; Dubonos, S. V.; Grigorieva, I. V.; Firsov, A. A., Electric Field Effect in Atomically Thin Carbon Films. Science 2004, 306, 666-669.

15. Novoselov, K. S.; Jiang, D.; Schedin, F.; Booth, T. J.; Khotkevich, V. V.; Morozov, S. V.; Geim, A. K., Two-dimensional atomic crystals. Proceedings of the National Academy of Sciences of the United States of America 2005, 102, 10451-10453.

16. Yang, W.; Chen, G.; Shi, Z.; Liu, C.-C.; Zhang, L.; Xie, G.; Cheng, M.; Wang, D.; Yang, R.; Shi, D.; Watanabe, K.; Taniguchi, T.; Yao, Y.; Zhang, Y.; Zhang, G., Epitaxial growth of single-domain graphene on hexagonal boron nitride. Nature Materials 2013, 12, 792-797.

17. Cambaz, Z. G.; Yushin, G.; Osswald, S.; Mochalin, V.; Gogotsi, Y., Noncatalytic synthesis of carbon nanotubes, graphene and graphite on SiC. Carbon 2008, 46, 841-849.

18. Kim, K. S.; Zhao, Y.; Jang, H.; Lee, S. Y.; Kim, J. M.; Kim, K. S.; Ahn, J.-H.; Kim, P.; Choi, J.-Y.; Hong, B. H., Large-scale pattern growth of graphene films for stretchable transparent electrodes. Nature 2009, 457, 706-710.

19. Chen, X.; Zhang, L.; Chen, S., Large area CVD growth of graphene. Synthetic Metals 2015, 210, 95-108.

20. Wang, J.; Manga, K. K.; Bao, Q.; Loh, K. P., High-Yield Synthesis of Few-Layer Graphene Flakes through Electrochemical Expansion of Graphite in Propylene Carbonate Electrolyte. Journal of the American Chemical Society 2011, 133, 8888-8891.

21. Lu, J.; Yang, J.-x.; Wang, J.; Lim, A.; Wang, S.; Loh, K. P., One-Pot Synthesis of Fluorescent Carbon Nanoribbons, Nanoparticles, and Graphene by the Exfoliation of Graphite in Ionic Liquids. ACS Nano 2009, 3, 2367-2375.
22. Qi, B.; He, L.; Bo, X.; Yang, H.; Guo, L., Electrochemical preparation of free-standing few-layer graphene through oxidation-reduction cycling. Chemical Engineering Journal 2011, $171,340-344$.

23. Liu, N.; Luo, F.; Wu, H.; Liu, Y.; Zhang, C.; Chen, J., OneStep Ionic-Liquid-Assisted Electrochemical Synthesis of IonicLiquid-Functionalized Graphene Sheets Directly from Graphite. Advanced Functional Materials 2008, 18, 1518-1525.

24. Liu, Z.; Zhang, H.; Eredia, M.; Qiu, H.; Baaziz, W.; Ersen, O.; Ciesielski, A.; Bonn, M.; Wang, H. I.; Samorì, P., WaterDispersed High-Quality Graphene: A Green Solution for Efficient Energy Storage Applications. ACS Nano 2019, 13, 9431-9441.

25. Compton, O. C.; Jain, B.; Dikin, D. A.; Abouimrane, A. Amine, K.; Nguyen, S. T., Chemically Active Reduced Graphene Oxide with Tunable C/O Ratios. ACS Nano 2011, 5, 4380-4391.

26. Goubaa, H.; Escobar-Teran, F.; Ressam, I.; Gao, W.; El Kadib, A.; Lucas, I. T.; Raihane, M.; Lahcini, M.; Perrot, H.; Sel, O. Dynamic Resolution of Ion Transfer in Electrochemically Reduced Graphene Oxides Revealed by Electrogravimetric Impedance. The Journal of Physical Chemistry C 2017, 121, 93709380.

27. Gao, W.; Debiemme-Chouvy, C.; Lahcini, M.; Perrot, H.; Sel, 0., Tuning Charge Storage Properties of Supercapacitive Electrodes Evidenced by In Situ Gravimetric and Viscoelastic Explorations. Analytical Chemistry 2019, 91, 2885-2893.

28. Guo, H.-L.; Wang, X.-F.; Qian, Q.-Y.; Wang, F.-B.; Xia, X.H., A Green Approach to the Synthesis of Graphene Nanosheets. ACS Nano 2009, 3, 2653-2659.

29. Banda, H.; Daffos, B.; Périé, S.; Chenavier, Y.; Dubois, L.; Aradilla, D.; Pouget, S.; Simon, P.; Crosnier, O.; Taberna, P.-L.; Duclairoir, F., Ion Sieving Effects in Chemically Tuned Pillared Graphene Materials for Electrochemical Capacitors. Chemistry of Materials 2018, 30, 3040-3047.

30. Banda, H.; Périé, S.; Daffos, B.; Taberna, P.-L.; Dubois, L.; Crosnier, O.; Simon, P.; Lee, D.; De Paëpe, G.; Duclairoir, F. Sparsely Pillared Graphene Materials for High-Performance Supercapacitors: Improving Ion Transport and Storage Capacity. ACS Nano 2019, 13, 1443-1453.

31. Fan, W.; Miao, Y.-E.; Huang, Y.; Tjiu, W. W.; Liu, T., Flexible free-standing 3D porous $\mathrm{N}$-doped graphene-carbon nanotube hybrid paper for high-performance supercapacitors. RSC Advances 2015, 5, 9228-9236.

32. Gorgolis, G.; Galiotis, C., Graphene aerogels: a review. 2 Materials 2017, 4, 032001.

33. He, Y.; Zhang, N.; Gong, Q.; Li, Z.; Gao, J.; Qiu, H., Metal nanoparticles supported graphene oxide 3D porous monoliths and their excellent catalytic activity. Materials Chemistry and Physics 2012, 134, 585-589.

34. Czepa, W.; Witomska, S.; Ciesielski, A.; Samorì, P., Reduced graphene oxide-silsesquioxane hybrid as a novel supercapacitor electrode. Nanoscale 2020, 12, 18733-18741.

35. Zakaria, M. B.; Li, C.; Ji, Q.; Jiang, B.; Tominaka, S.; Ide, Y.; Hill, J. P.; Ariga, K.; Yamauchi, Y., Self-Construction from 2D to 3D: One-Pot Layer-by-Layer Assembly of Graphene Oxide Sheets Held Together by Coordination Polymers. Angewandte Chemie International Edition 2016, 55, 8426-8430.

36. Lee, H.; Dellatore, S. M.; Miller, W. M.; Messersmith, P. B., Mussel-Inspired Surface Chemistry for Multifunctional Coatings. Science 2007, 318, 426-430.

37. Liu, Y.; Ai, K.; Lu, L., Polydopamine and Its Derivative Materials: Synthesis and Promising Applications in Energy, 
Environmental, and Biomedical Fields. Chemical Reviews 2014, 114, 5057-5115.

38. Jeong, Y. K.; Park, S. H.; Choi, J. W., Mussel-Inspired Coating and Adhesion for Rechargeable Batteries: A Review. ACS Applied Materials \& Interfaces 2018, 10, 7562-7573.

$39 . \quad H u a n g$, Q.; Chen, J.; Liu, M.; Huang, H.; Zhang, X.; Wei, Y., Polydopamine-based functional materials and their applications in energy, environmental, and catalytic fields: State-of-the-art review. Chemical Engineering Journal 2020, 387, 124019.

$40 . \quad$ Ryou, M.-H.; Lee, Y. M.; Park, J.-K.; Choi, J. W., MusselInspired Polydopamine-Treated Polyethylene Separators for High-Power Li-Ion Batteries. Advanced Materials 2011, 23, 30663070 .

41. Cho, I.; Gong, S.; Song, D.; Lee, Y.-G.; Ryou, M.-H.; Lee, Y. M., Mussel-inspired Polydopamine-treated Copper Foil as a Current Collector for High-performance Silicon Anodes. Scientific Reports 2016, 6, 30945.

42. Sigalov, S.; Levi, M. D.; Salitra, G.; Aurbach, D.; Maier, J., EQCM as a unique tool for determination of ionic fluxes in microporous carbons as a function of surface charge distribution. Electrochemistry Communications 2010, 12, 1718-1721.

43. Tsai, W.-Y.; Taberna, P.-L.; Simon, P., Electrochemical Quartz Crystal Microbalance (EQCM) Study of Ion Dynamics in Nanoporous Carbons. Journal of the American Chemical Society 2014, 136, 8722-8728.

44. Hillman, A. R., The EQCM: electrogravimetry with a light touch. Journal of Solid State Electrochemistry 2011, 15, $1647-1660$

45. Escobar-Teran, F.; Arnau, A.; Garcia, J. V.; Jiménez, Y.; Perrot, H.; Sel, O., Gravimetric and dynamic deconvolution of global EQCM response of carbon nanotube based electrodes by Ac-electrogravimetry. Electrochemistry Communications 2016, 70, 73-77.

46. Shao, Y.; Wang, J.; Engelhard, M.; Wang, C.; Lin, Y., Facile and controllable electrochemical reduction of graphene oxide and its applications. Journal of Materials Chemistry 2010, 20, 743-748.

47. Banda, H.; Aradilla, D.; Benayad, A.; Chenavier, Y.; Daffos, B.; Dubois, L.; Duclairoir, F., One-step synthesis of highly reduced graphene hydrogels for high power supercapacitor applications. Journal of Power Sources 2017, 360, 538-547.

48. Nazi, N.; Humblot, V.; Debiemme-Chouvy, C., A New Antibacterial N-Halamine Coating Based on Polydopamine. Langmuir 2020, 36, 11005-11014.

49. Lé, T.; Aradilla, D.; Bidan, G.; Billon, F.; Delaunay, M.; Gérard, J. M.; Perrot, H.; Sel, O., Unveiling the ionic exchange mechanisms in vertically-oriented graphene nanosheet supercapacitor electrodes with electrochemical quartz crystal microbalance and ac-electrogravimetry. Electrochemistry Communications 2018, 93, 5-9.

50. Zhu, Y.; Murali, S.; Stoller, M. D.; Ganesh, K. J.; Cai, W.; Ferreira, P. J.; Pirkle, A.; Wallace, R. M.; Cychosz, K. A.; Thommes, M.; Su, D.; Stach, E. A.; Ruoff, R. S., Carbon-Based Supercapacitors Produced by Activation of Graphene. Science 2011, 332, 15371541.

51. Ardizzone, S.; Fregonara, G.; Trasatti, S., Inner and outer active surface of $\mathrm{RuO}_{2}$ electrodes. Electrochimica Acta 1990, 35, 263-267.

52. Wang, C.; Liu, F.; Chen, J.; Yuan, Z.; Liu, C.; Zhang, X.; Xu, M.; Wei, L.; Chen, Y., A graphene-covalent organic framework hybrid for high-performance supercapacitors. Energy Storage Materials 2020, 32, 448-457.
53.

Chen, L.-F.; Zhang, X.-D.; Liang, H.-W.; Kong, M.; Guan, Q.-F.; Chen, P.; Wu, Z.-Y.; Yu, S.-H., Synthesis of Nitrogen-Doped Porous Carbon Nanofibers as an Efficient Electrode Material for Supercapacitors. ACS Nano 2012, 6, 7092-7102.

54. Tao, Y.; Xie, X.; Lv, W.; Tang, D.-M.; Kong, D.; Huang, Z.; Nishihara, H.; Ishii, T.; Li, B.; Golberg, D.; Kang, F.; Kyotani, T. Yang, Q.-H., Towards ultrahigh volumetric capacitance: graphene derived highly dense but porous carbons for supercapacitors. Scientific Reports 2013, 3, 2975.

55. Wong, S. I.; Sunarso, J.; Wong, B. T.; Lin, H.; Yu, A.; Jia, B., Towards enhanced energy density of graphene-based supercapacitors: Current status, approaches, and future directions. Journal of Power Sources 2018, 396, 182-206.

56. Ferris, A.; Garbarino, S.; Guay, D.; Pech, D., 3D $\mathrm{RuO}_{2}$ Microsupercapacitors with Remarkable Areal Energy. Advanced Materials 2015, 27, 6625-6629.

57. Agrawal, R.; Wang, C., On-Chip Asymmetric Microsupercapacitors Combining Reduced Graphene Oxide and Manganese Oxide for High Energy-Power Tradeoff. Micromachines (Basel) 2018, 9, 399.

58. Kötz, R.; Carlen, M., Principles and applications of electrochemical capacitors. Electrochimica Acta 2000, 45, 2483 2498.

59. Taberna, P. L.; Simon, P.; Fauvarque, J. F., Electrochemical Characteristics and Impedance Spectroscopy Studies of Carbon-Carbon Supercapacitors. Journal of The Electrochemical Society 2003, 150, A292-A300.

60. Cougnon, C.; Lebègue, E.; Pognon, G., Impedance spectroscopy study of a catechol-modified activated carbon electrode as active material in electrochemical capacitor. Journal of Power Sources 2015, 274, 551-559.

61. Ye, J.; Wu, Y.-C.; Xu, K.; Ni, K.; Shu, N.; Taberna, P.-L.; Zhu, Y.; Simon, P., Charge Storage Mechanisms of Single-Layer Graphene in Ionic Liquid. Journal of the American Chemical Society 2019, 141, 16559-16563.

62. Pan, C.; Gu, H.; Dong, L., Synthesis and electrochemical performance of polyaniline @ $\mathrm{MnO}_{2}$ /graphene ternary composites for electrochemical supercapacitors. Journal of Power Sources 2016, 303, 175-181.

63. Bandyopadhyay, P.; Kuila, T.; Balamurugan, J.; Nguyen, T. T.; Kim, N. H.; Lee, J. H., Facile synthesis of novel sulfonated polyaniline functionalized graphene using m-aminobenzene sulfonic acid for asymmetric supercapacitor application. Chemical Engineering Journal 2017, 308, 1174-1184.

64. Sauerbrey, G., Verwendung von Schwingquarzen zur Wägung dünner Schichten und zur Mikrowägung. Zeitschrift für Physik 1959, 155, 206-222.

65. Bizet, K.; Gabrielli, C.; Perrot, H., Immunodetection by quartz crystal microbalance. Applied Biochemistry and Biotechnology 2000, 89, 139.

66. Lemaire, P.; Dargon, T.; Alves Dalla Corte, D.; Sel, O.; Perrot, H.; Tarascon, J.-M., Making Advanced Electrogravimetry as an Affordable Analytical Tool for Battery Interface Characterization. Analytical Chemistry 2020, 92, 13803-13812. 


\section{Table of Contents}

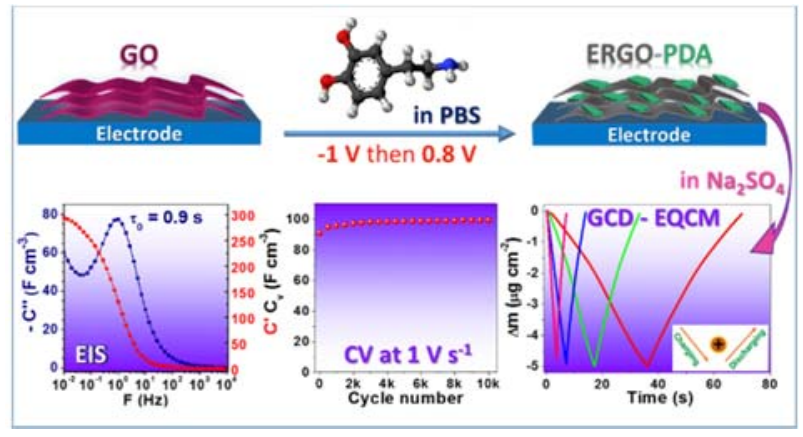




\section{Supporting Information}

\section{Preventing graphene from restacking via bioinspired chemical inserts: toward superior 2D micro-supercapacitor electrode performance}

\section{Adnane Bouzina, Hubert Perrot, Ozlem Sel*, and Catherine Debiemme-Chouvy*}

Sorbonne Université, CNRS, Laboratoire Interfaces et Systèmes Electrochimiques,

LISE, F-75005 Paris, France

$\underline{\text { ozlem.sel@sorbonne-universite.fr }}$

catherine.debiemme-chouvy@,sorbonne-universite.fr

Table S1. Chemical compositions in atom \% calculated from XPS data for GO, ERGO and ERGO-PDA films and theoretical values for PDA.

\begin{tabular}{|c|c|c|c|}
\hline & C & O & N \\
\hline GO & 75 & 25 & - \\
\hline ERGO & 89 & 11 & 5 \\
\hline ERGO-PDA & 77 & 18 & 9 \\
\hline \hline PDA & 73 & 18 & \\
\hline
\end{tabular}
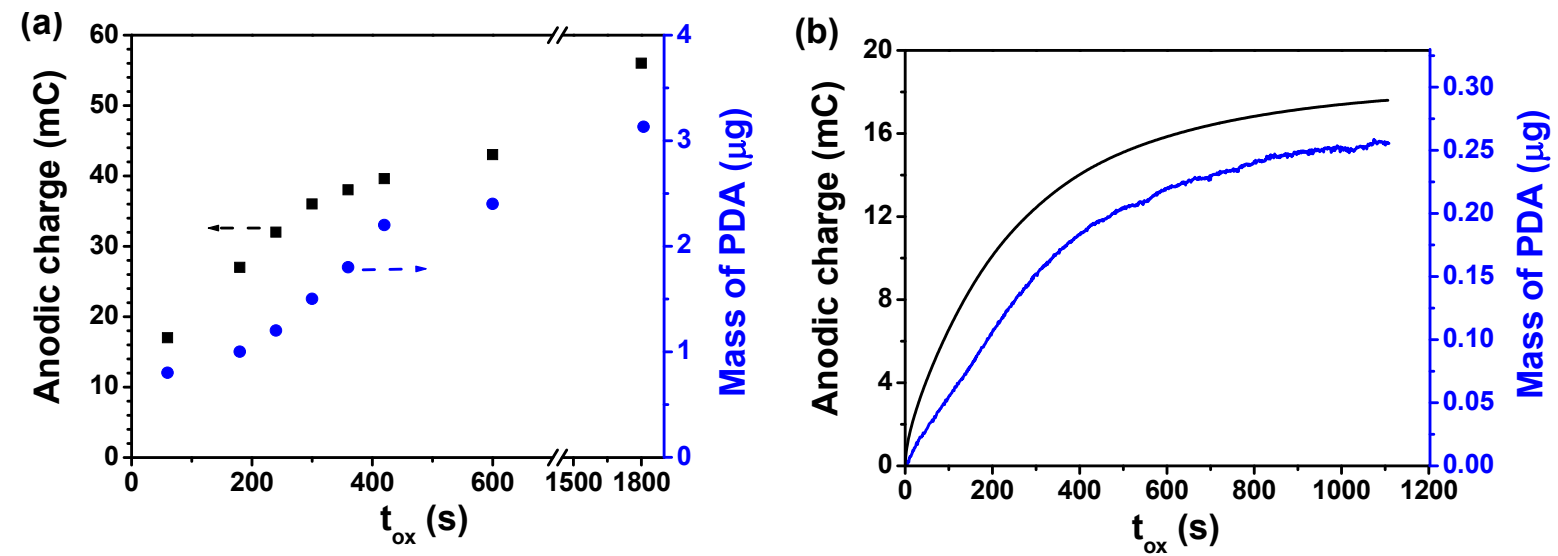

Figure S1. Anodic charge and mass change vs. duration of applying a potential at which the dopamine is oxidized ( $0.8 \mathrm{~V}$ vs. SCE) in $0.5 \mathrm{M}$ PBS $+5 \mathrm{mM}$ dopamine. (a) on ERGO coated $\mathrm{Au}$ electrode of quartz (each point corresponds to a different experiment). (b) on bare $\mathrm{Au}$ electrode of quartz, the PDA electrodeposition is performed continuously. 

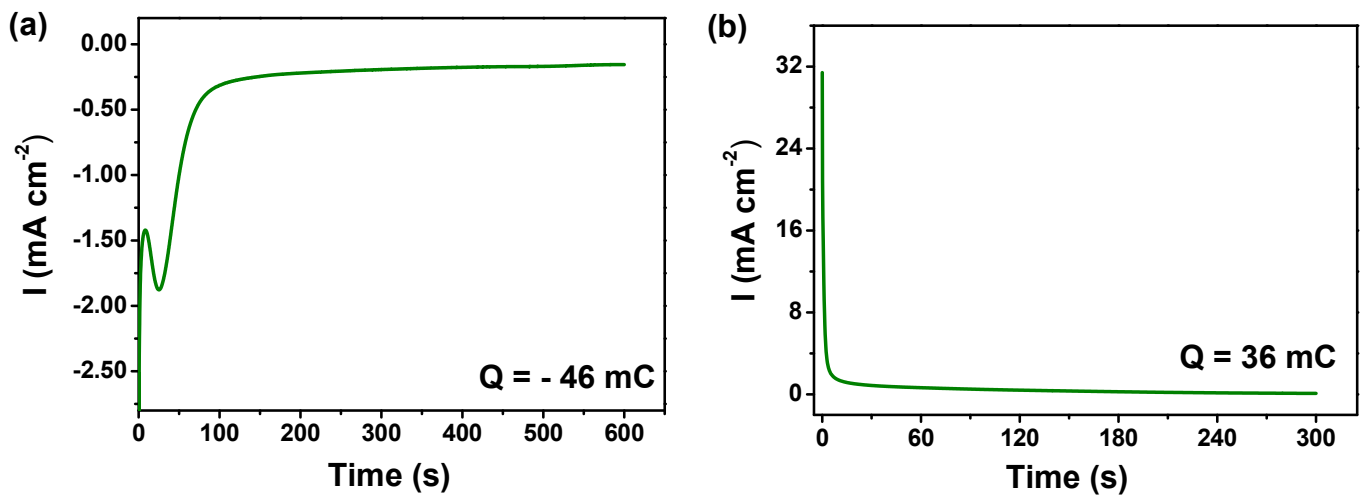

Figure S2. Electrochemical preparation of the composite ERGO-PDA. (a) Current density $v s$. time at GO-coated quartz electrode polarized at $-1 \mathrm{~V} v s$. SCE, (b) Current density vs. time at ERGO-coated quartz electrode polarized at $0.8 \mathrm{~V} v s$. SCE. Both polarizations are performed in the same solution of $0.2 \mathrm{M}$ PBS containing $5 \mathrm{mM}$ of dopamine.
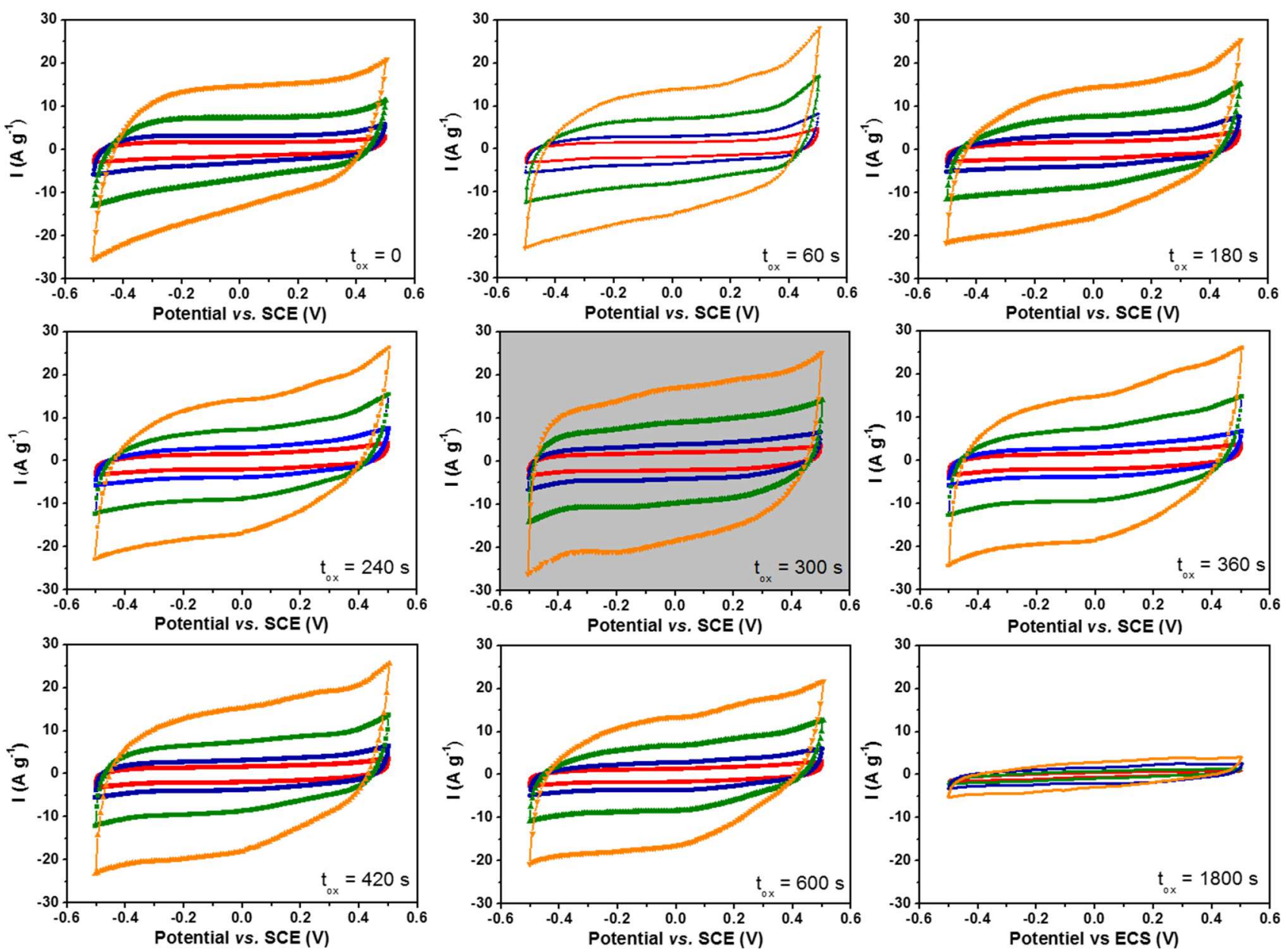

Figure S3. CV curves of ERGO and ERGO-PDA prepared with various electro-oxidation (at $0.8 \mathrm{~V} / \mathrm{SCE}$ ) times $\left(t_{o x}\right)$ of dopamine in $0.5 \mathrm{M} \mathrm{Na}_{2} \mathrm{SO}_{4}$ solution. Scan rate: 10 (red line), 20 (blue line), 50 (green line), 100 (orange line) $\mathrm{mV} \mathrm{s}^{-1}$. Optimized composition is obtained for $t_{o x}=300$ $\mathrm{s}$, highlighted in grey. 

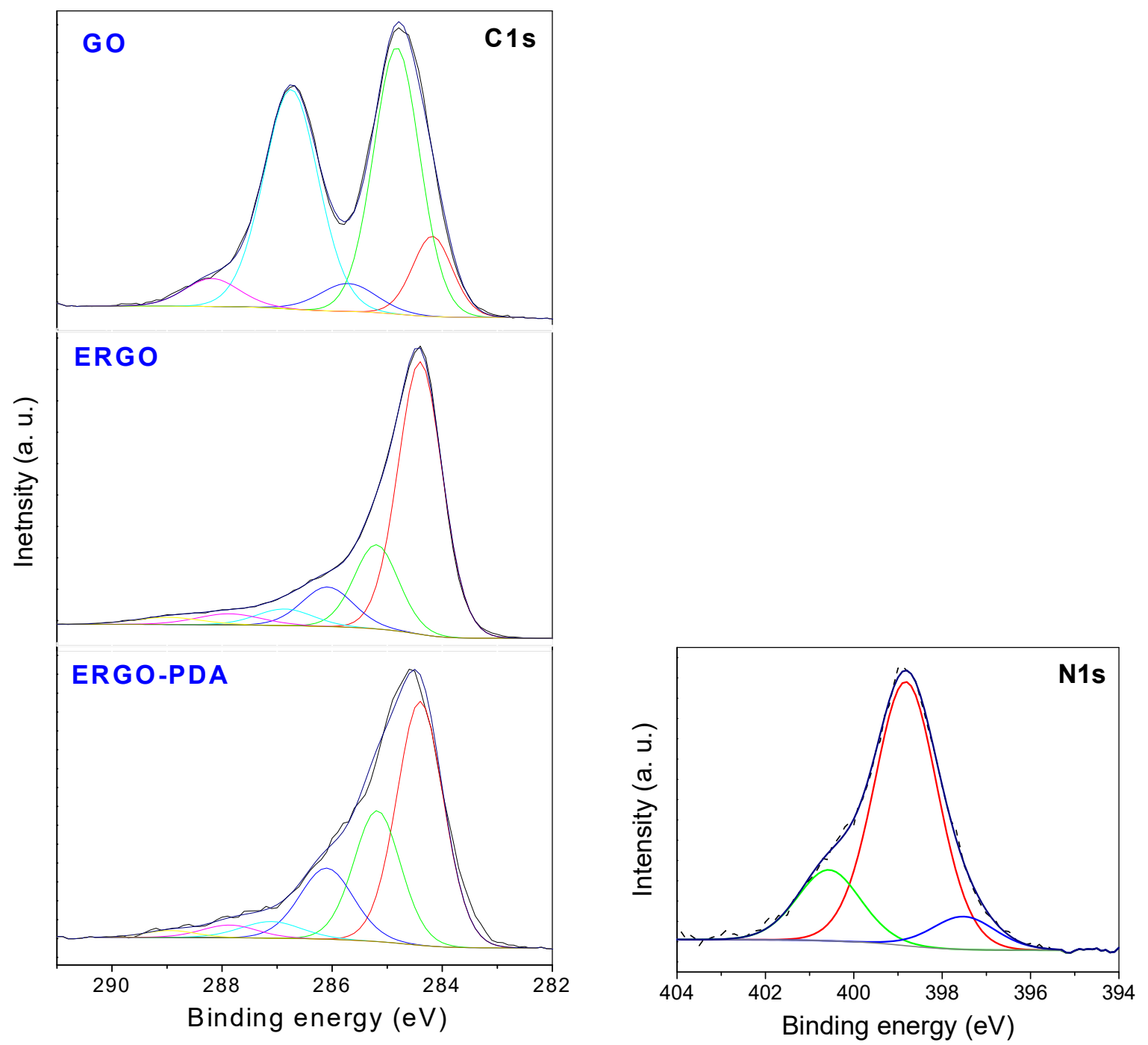

Figure S4. C1s XPS spectra of GO, ERGO and ERGO-PDA samples and N1s spectrum from ERGO-PDA film. 

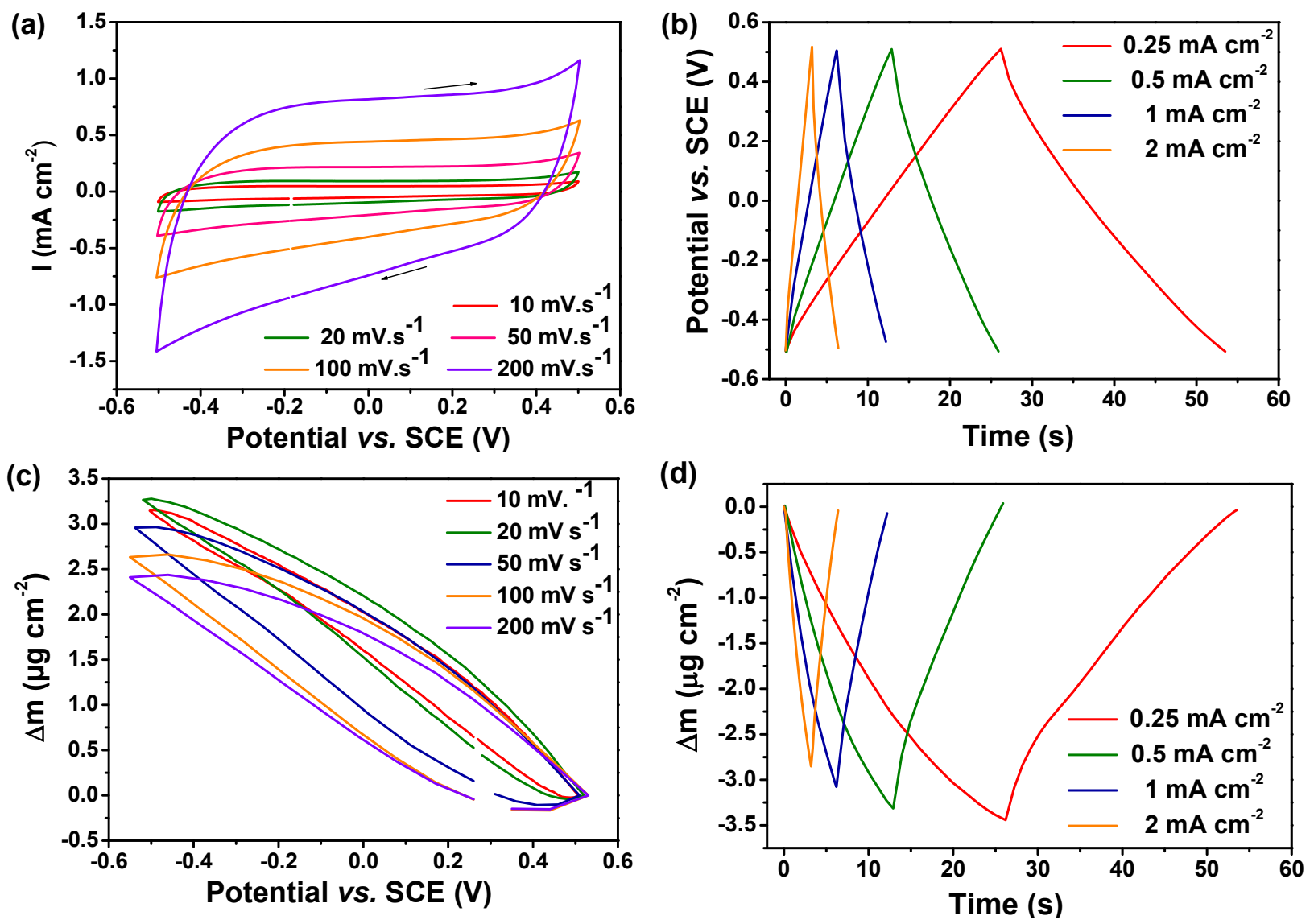

Figure S5. (a) CV and (c) mass variation of ERGO at different potential scan rates, (b) GCD and (d) mass variation of ERGO at different charge/discharge current densities in $0.5 \mathrm{M}$ $\mathrm{Na}_{2} \mathrm{SO}_{4}$.

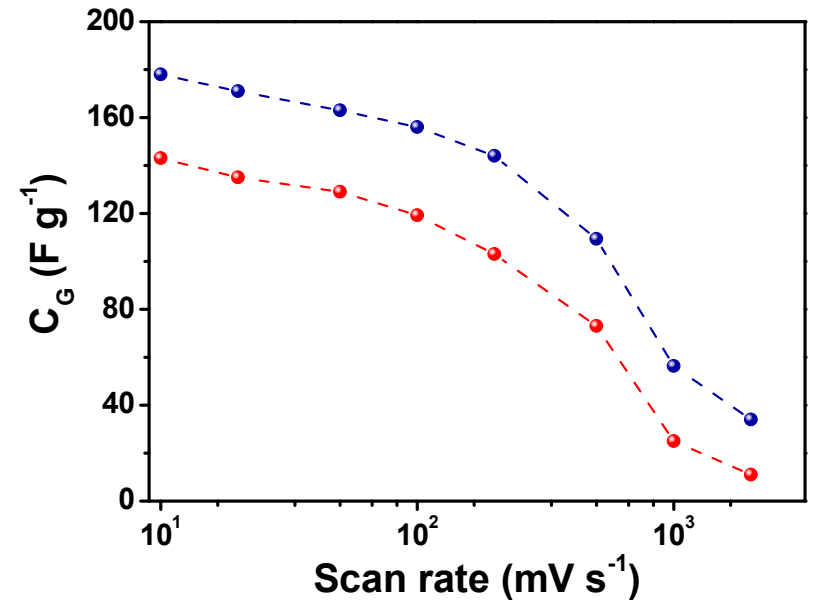

Figure S6. Gravimetric capacitance of ERGO (red scatters) and ERGO-PDA (blue scatters) films determined from CVs performed at different potential scan rates, in $0.5 \mathrm{M} \mathrm{Na}_{2} \mathrm{SO}_{4}$. 

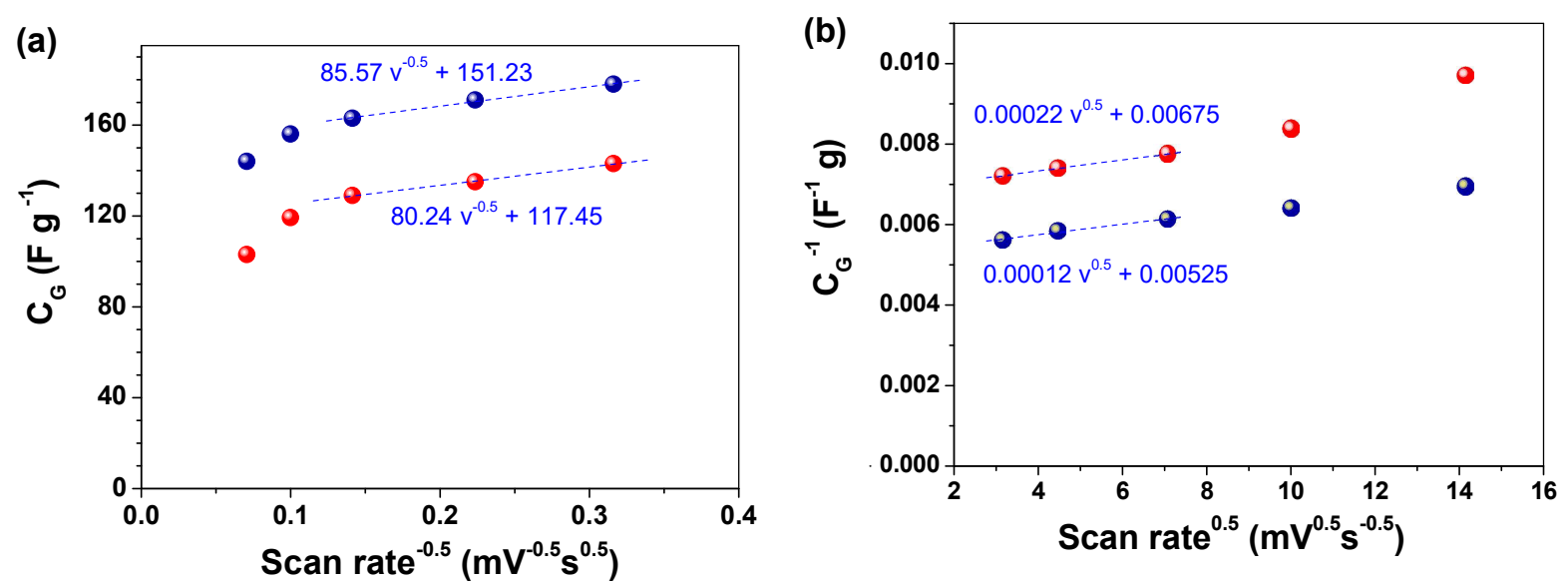

Figure S7. (a) Gravimetric capacitance of ERGO (red scatters) and ERGO-PDA (blue scatters) $v s$. reciprocal of the square root of potential scan rate. (b) Reciprocal of the gravimetric capacitance $v s$. the square root of potential scan rate.

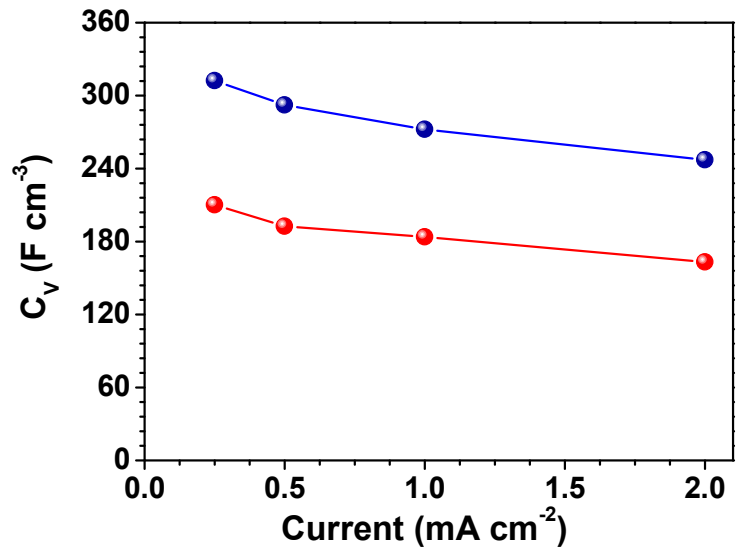

Figure S8. Volumetric capacitance of ERGO (red scatters) and ERGO-PDA (blue scatters) calculated from GCD curves. 


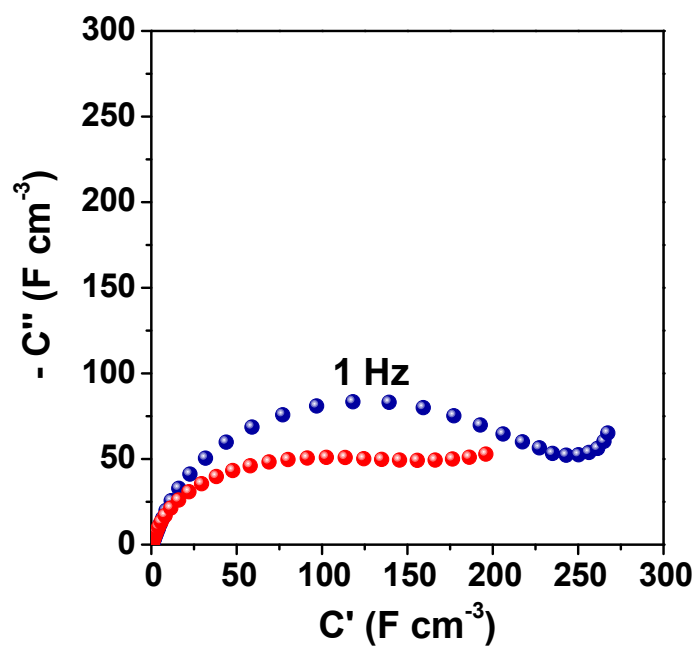

Figure S9. Complex capacitance plot of ERGO (red scatters) and ERGO-PDA (blue scatters) in the frequency range of $0.01 \mathrm{~Hz}$ to $10 \mathrm{kHz}$, measured at $-0.3 \mathrm{~V}$ vs. SCE in $0.5 \mathrm{M} \mathrm{Na}_{2} \mathrm{SO}_{4}$.

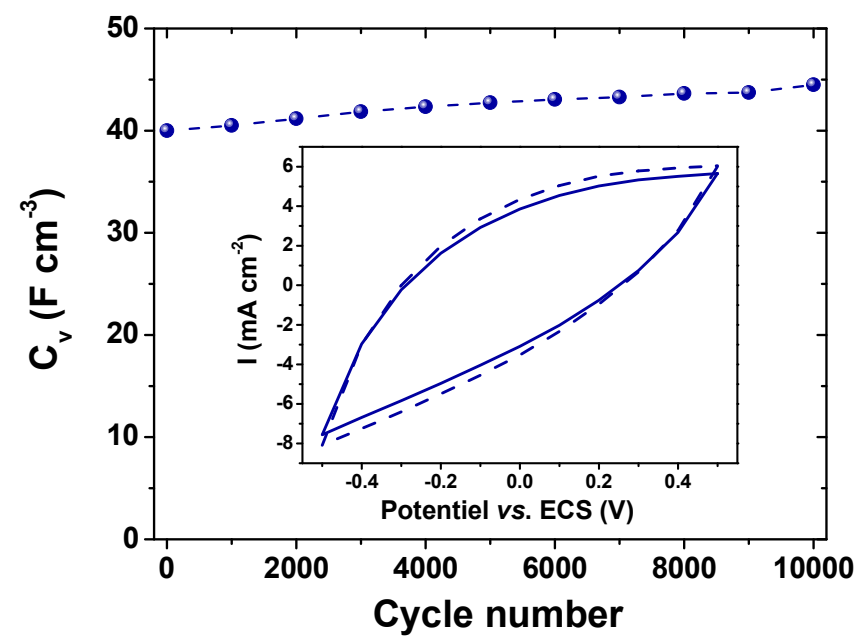

Figure S10. Evolution of volumetric capacitance of ERGO-PDA as a function of the number of cycles at $2000 \mathrm{mV} \cdot \mathrm{s}^{-1}$. Electrolyte: $0.5 \mathrm{M} \mathrm{Na}_{2} \mathrm{SO}_{4}$. Inserts: $1^{\text {st }}$ (full line) and $10000^{\text {th }}$ (dash line) cycles.

(a)

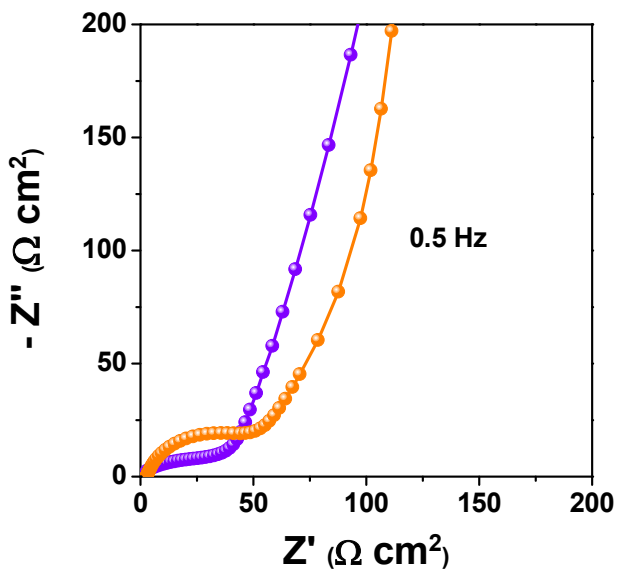

(b)

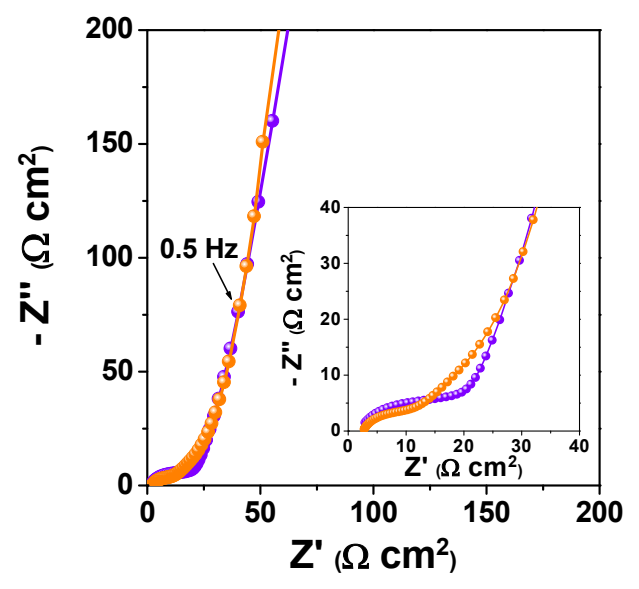

Figure

S11. Nyquist plots of (a) ERGO and (b) ERGO-PDA before (purple scatters) and after 10000 cycles (orange scatters), measured at $-0.3 \mathrm{~V} v s$. SCE in $0.5 \mathrm{M} \mathrm{Na}_{2} \mathrm{SO}_{4}$. Inset: zoom from 0 to $40 \Omega \cdot \mathrm{cm}^{2}$. 


\section{Electroacoustic admittance measurements}

A QCM device consists of a thin AT cut quartz crystal disc (or any other piezoelectric material) with circular electrodes placed on both sides. An alternating voltage, applied between its electrodes, induces mechanical oscillations on the crystal. A wave is generated and propagated through the resonator and the films attached to it. Therefore, varying the mass attached to one side of the electrode affects the QCM resonant frequency. The fundamental theory describing the relationship between the mass changes on the surface of the QCM electrode with the frequency change of the oscillating quartz was described by Sauerbrey: ${ }^{[1]}$

$\Delta f=-C_{f} \cdot \Delta m$

where $\Delta f$ is the observed frequency change, in $\mathrm{Hz}, \Delta m$ is the change in mass per unit area, in $\mathrm{g} \cdot \mathrm{cm}^{-2}, C_{f}$ is the experimental sensitivity factor obtained by usual copper electrodeposition $\left(16.31 \times 10^{7} \mathrm{~Hz} \cdot \mathrm{g}^{-1} \cdot \mathrm{cm}^{2}\right.$ for a $9 \mathrm{MHz}$ AT-cut quartz crystal at room temperature). ${ }^{[2]}$

However, the Sauerbrey equation is strictly applicable to homogeneous, rigid, flat surface thin films which do not dissipate significant amount of energy during oscillation. ${ }^{[3]}$ Therefore, the suitability of the Sauerbrey equation to interpret $\Delta f$ of a QCM during a process has to be verified.

The electroacoustic admittance measurements are considered as a powerful method to study the energy loss of acoustic wave generated from piezoelectric electrode resonance. For the electroacoustic analysis of a coated quartz resonator, the electrical admittance of the quartz resonator around its own resonant frequency is measured. ${ }^{[4-5]}$ This analysis provides the possibility to separate the contribution of the film viscoelasticity (if there is any) to the mass measurements. One possibility to extract the mechanical/structural and viscoelastic transformations of coatings is to model the electroacoustic response of the quartz crystal resonators with an electrical equivalent circuit, known as a Butterworth-Van Dyke (BVD) equivalent circuit (Figure S12). ${ }^{[6]}$ A BVD equivalent circuit consists of two branches that represent a static capacitance $\left(\mathrm{C}_{0}\right)$ in parallel with a motional branch with the motional inductance, $\mathrm{L}_{1}$, the motional capacitance, $\mathrm{C}_{1}$, and the motional resistance, $\mathrm{R}_{1}$, in series. 


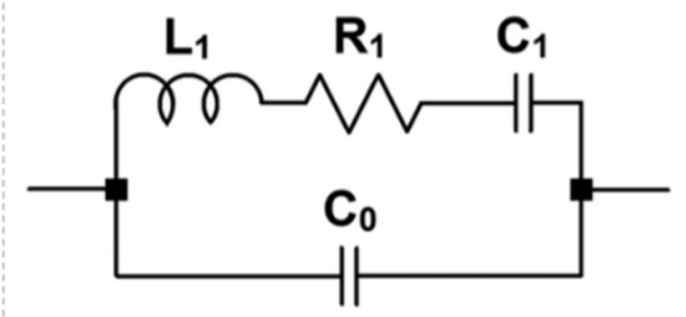

Figure S12. Butterworth-Van Dyke model.

Despite $\mathrm{R}_{1}$ being an electric magnitude, it can be interpreted by an electromechanical analogy. $\mathrm{R}_{1}$ is related to the energy loss of acoustic wave generated from piezoelectric electrode resonance and has been used as an indicator for viscoelastic property changes of materials deposited on the QCM resonator and the hydrodynamic interactions of these materials in contact with liquids. ${ }^{[7-9]}$

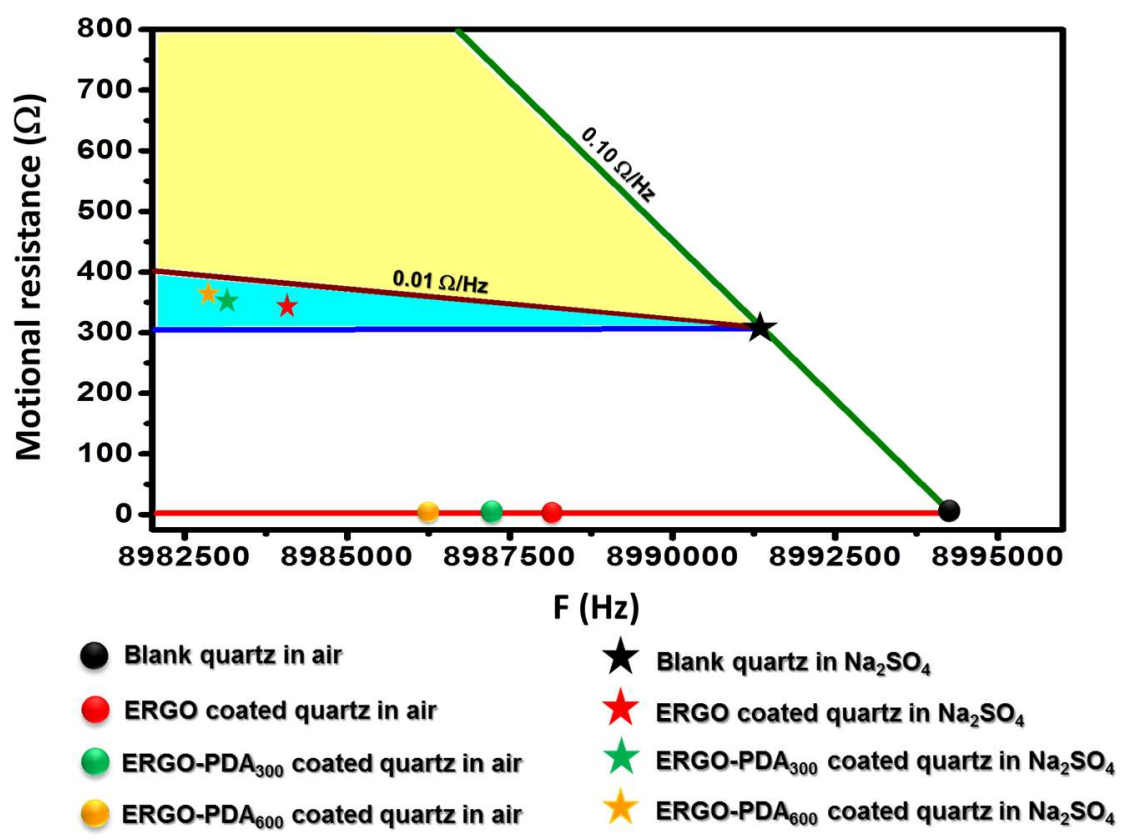

Figure S13. Change of resonance frequency and motional resistance as a function of the film $\left(\mathrm{ERGO}\right.$ ERGO-PDA $300\left(t_{o x}=300 \mathrm{~s}\right)$ and ERGO-PDA $\left.600\left(t_{o x}=600 \mathrm{~s}\right)\right)$ deposited on the quartz, in air (circles) and in $0.5 \mathrm{M} \mathrm{Na}_{2} \mathrm{SO}_{4}$ solution (stars).

In our case, the electroacoustic measurements have been performed to verify the applicability of the gravimetric regime (Sauerbrey equation to interpret $\Delta f$ using Equation S1) on our coatings. To this end, the motional resistance and the resonant frequency of the quartz with and without loading in the air and in the electrolyte were registered by using a network analyzer (Agilent 4294A impedance analyzer). The resonant frequency was obtained from the maximum 
of the real part of the electroacoustic admittance and the typical Butterworth-Van Dyke (BVD) equivalent circuit was used to fit this admittance to extract the values of the motional resistance. The obtained values were used to obtain Figure S13 which compares R1 to the resonant frequency of various quartz resonators with ERGO and ERGO-PDA coatings, in air and in the electrolyte.

According to Figure S13, the measurements in air show that the motional resistance of the quartz remains almost constant after the deposition of the ERGO and the PDA for $300 \mathrm{~s}$ and $600 \mathrm{~s}(6 \Omega<\mathrm{R} 1<8 \Omega)$, ensuring the gravimetric regime of the coating in air (the red line). In $0.5 \mathrm{M} \mathrm{Na}_{2} \mathrm{SO}_{4}$ aqueous solution, expectedly, the existence of a liquid load causes a sharp increase of R1 (from a few ohms in air to a few hundred ohms in solution) and leads to a resonance damping, which consequently decreases the resonant frequency (the green line in Figure S13). This behavior is explained by Kanazawa-Gordon equation. ${ }^{[10]}$ For a bare quartz resonator operating at $9 \mathrm{MHz}$, air to liquid medium change gives $\Delta R_{m} / \Delta f$ values of $\sim 0.1 \Omega$. $\mathrm{Hz}^{-}$

1 , which agrees well with the value obtained for the green line.

The measured values for the loaded resonators in the electrolyte, the $\Delta R_{m} / \Delta f$, fall in the reliability region for application of the Sauerbrey equation, where $\Delta \mathrm{R}(\Omega)<<\Delta \mathrm{f}(\mathrm{Hz})$. The upper limit of this region is defined in the literature with the condition of $\Delta \mathrm{R}(\Omega) / \Delta \mathrm{f}(\mathrm{Hz})<$ $0.01 \Omega / \mathrm{Hz}$ (where the lower limit is the ideal case of $\Delta R_{m} / \Delta f$ ratio is equal to 0 ) (the blue area $[11]$.

\section{References}

(1) Sauerbrey, G. Use of quartz vibration for weighing thin films on a microbalance. Z. Phys. 1959, 155, 206-212.

(2) Bizet, K.; Gabrielli, C.; Perrot, H., Immunodetection by quartz crystal microbalance. Appl. Biochem. Biotechnol. 2000, 89, 139.

(3) Buttry, D. "Applications of the QCM to electrochemistry", in A Series of Advances in Electroanalytical Chemistry, edited by Allen Bard, Marcel Dekker, 1991, p. 23-33.

(4) Gabrielli, C.; Magalhaes, A. A. O.; Margarit, I. C. P.; Perrot, H.; Tribollet, B., Study of chromate-zinc conversion process through microbalance/electroacoustic impedance coupling measurements. Electrochem. Comm. 2004, 6, 492-498.

(5) Gao, W.; Debiemme-Chouvy, C.; Lahcini, M.; Perrot, H.; Sel, O., Tuning Charge Storage Properties of Supercapacitive Electrodes Evidenced by In Situ Gravimetric and Viscoelastic Explorations. Anal. Chem. 2019, 91, p.2885-2893. 
(6) Alassi, A.; Benammar, M.; Brett, D., Quartz Crystal Microbalance Electronic Interfacing Systems: A Review. Sensors 2017, 17, 2799 (41 p).

(7) Lemaire, P.; Dargon, T.; Alves Dalla Corte, D.; Sel, O.; Perrot, H.; Tarascon, J.-M., Making Advanced Electrogravimetry as an Affordable Analytical Tool for Battery. Interface Characterization. Anal. Chem. 2020, 92, 13803-13812.

(8) Plausinaitis, D.; Ratautaite, V.; Mikoliunaite, L.; Sinkevicius, L.; Ramanaviciene, A.; Ramanavicius, A., Quartz Crystal Microbalance-Based Evaluation of the Electrochemical Formation of an Aggregated Polypyrrole Particle-Based Layer. Langmuir 2015, 31, 31863193.

(9) Agrisuelas, J.; Gabrielli, C.; García-Jareño, J. J.; Perrot, H.; Sel, O.; Vicente, F.,Viscoelastic potential-induced changes in acoustically thin films explored by quartz crystal microbalance with motional resistance monitoring. Electrochim. Acta 2015, 176, $1454-1463$.

(10) Keiji Kanazawa, K.; Gordon, J. G., The oscillation frequency of a quartz resonator in contact with liquid. Anal. Chim. Acta 1985, 175, 99-105.

(11) Muramatsu, H.; Egawa, A.; Ataka, T., Reliability of correlation between mass change and resonant frequency change for a viscoelastic-film-coated quartz crystal. $J$. Electroanal.Chem. 1995, 388, 89-92. 